\title{
Escenarios relativos al establecimiento de agenda para la gobernanza transgeneracional de los recursos y servicios hídricos ${ }^{1}$
}

\section{Scenarios regarding the establishment of an agenda for transgenerational governance of water resources and services}

Recibido: 03 de junio de 2015 - Revisado: 09 de enero de 2016 - Aceptado: 12 de abril de 2016

Cruz García Lirios ${ }^{2}$

Javier Carreón Guillén ${ }^{3}$

José Marcos Bustos Aguayo ${ }^{4}$

Marjarita Juárez Najera ${ }^{5}$

\begin{abstract}
Resumen
A partir de una revisión de escenarios económicos, políticos, ambientales, sanitarios, sociales y psicológicos se llevó a cabo un estudio documental con una selección de fuentes indexadas en repositorios de América Latina -Dialnet, Latindex y Redalyc-, considerando el periodo que va de 1987 a 2016 y con la finalidad de especificar diez modelos para el estudio de la gobernanza de los recursos y servicios hídricos. En relación con otras revisiones se contrastan los modelos especificados y se recomienda incluir variables relacionadas con el establecimiento de agenda, factor clave para explicar la influencia de las políticas públicas sobre el comportamiento de usuarios del servicio de agua potable.
\end{abstract}

Palabras clave

Recursos hídricos, servicio de agua, gobernanza, agenda, escenarios.

\begin{abstract}
Based on a review of economic, political, environmental, health, social and psychological scenarios, a documentary study was conducted with a selection of sources indexed in Latin American repositories -Dialnet, Latindex and Redalyc--, considering the period from 1987 to 2016 and with the purpose of specifying ten models for the study of the governance of water resources and services. In relation to other reviews, the specified models are contrasted and it is recommended to include variables related to the agenda establishment, a key factor to explain the influence of public policies on the behavior of users of the potable water service.
\end{abstract}

\section{Keywords}

Water resources, water service, governance, agenda, scenarios.
1 Artículo financiado por el Consejo Nacional de Ciencia y Tecnología (CONACYT) mediante el otorgamiento de beca para estudios de Doctorado en Psicología, Universidad Nacional Autónoma de México.

${ }^{2}$ Estudios de Doctorado en Psicología, Profesor de Asignatura, Universidad Autónoma del Estado de México, Unidad Académica Profesional, Estado de México.

Correo electrónico:

cgarcial213@profesor.uaemex.mx

${ }^{3}$ Doctor en Administración, Profesor de Carrera Titular "B", Universidad Nacional Autónoma de México, Escuela Nacional de Trabajo Social, Coyoacán, México.

Correo electrónico: javierg@unam.mx

${ }^{4}$ Doctor en Psicología, Profesor de Carrera Titular "C", Universidad Nacional Autónoma de México, Facultad de Estudios Superiores, Zaragoza, México.

Correo electrónico:

marcos.bustos@unam.mx

5 Doctora en Psicología, Profesora Investigadora, Universidad Autónoma Metropolitana, Azcapotzalco, México. Correo electrónico:

mjn@correo.azc.uam.mx

Para citar este artículo use: García, C., Carreón, J., Bustos, J., \& Juárez, M. (2016). Escenarios relativos al establecimiento de agenda para la gobernanza transgeneracional de los recursos y servicios hídricos. Civilizar Ciencias Sociales y Humanas, 16(31), 83-112. 


\section{Introducción}

La discusión en torno a la administración de los recursos y servicios hídricos se ha centrado en las diferencias entre grupos en contra y a favor de la gestión del servicio de agua potable con base en tarifas y en función del volumen de agua consumido. En este sentido, el debate se ha enriquecido con la inclusión de perspectivas políticas, sociales y psicológicas, aun cuando el estado del conocimiento se acera gracias a los enfoques ambientales y sanitarios.

La administración pública de los recursos hídricos no solo considera al servicio de agua potable como un bien común, privado o público, sino además avanza hacia una concepción del abastecimiento de agua como un derecho civil para el desarrollo humano sustentable. En este sentido, la emergencia de una gestión pública con la participación ciudadana dirime los conflictos entre los actores económicos, políticos, sociales y comunitarios, así como el establecimiento de contiendas, acuerdos y corresponsabilidades.

Se trata de un sistema de gestión política y autogestión ciudadana que se conoce como gobernanza que, en el caso de los servicios hídricos tiene su indicador en la construcción de una agenda en la que se incluyen los temas prioritarios por y para los actores.

La gobernanza de los servicios hídricos estriba en: a) la difusión sistemática de temas -disponibilidad hídrica, derecho al agua, servicio de abastecimiento, sistema de cobro, subsidio y condonación, ahorro y reutilización de agua, y enfermedades hidrotransmitidaspreponderantes en los noticieros de televisión y radio, columnas de análisis de la prensa, documentales y redes sociales digitales; b) la formación de una opinión emocional o racional pública según el contexto, la fuente, el mensaje, la audiencia y el objeto; y c) la acción social y la movilización colectiva en torno a conflictos entre los actores -cierres de avenidas, secuestros de pipas y boicots al suministro-.
En tal proceso, el establecimiento de la agenda es un factor clave. Si los temas fijados refieren al derecho al acceso y consumo de agua, la opinión pública emergerá como un debate entre la administración pública y la gestión civil, pero si los temas apuntan a la ineficiencia administrativa y gestora, la discusión se centrará en la privatización de los acuíferos y la autogestión de las comunidades.

Por consiguiente, el objetivo del presente trabajo es comparar los escenarios económicos, políticos, ambientales, sanitarios, sociales y psicológicos de la gobernanza de los recursos y servicios hídricos. Para tal propósito, se llevó un estudio documental con una selección de fuentes indexadas en repositorios de América Latina -Dialnet, Latindex y Redalyc-, considerando el registro ISSN, ISBN y DOI de 1987 a 2016. La información se procesó en una matriz de análisis de contenido mediante la técnica de síntomas y reseña de hallazgos. Se construyeron esquemas conceptuales para la exposición de cada escenario, teniendo en cuenta sus asimetrías con respecto a teorías, conceptos y hallazgos.

\section{Escenarios económicos de la gobernanza de los servicios hídricos}

El agua, como recurso, ha sido administrada según su grado de disponibilidad y abastecimiento. De este modo, los recursos hídricos al asumirse como un bien público suponen contingencias ambientales derivadas del cambio climático que transformarán las disposiciones de los usuarios. Si más bien son considerados recursos privados, entonces el sistema de tarifas, subsidios y subvenciones resalta como elemento central de las políticas públicas. Por último, si se toman como bienes comunes, entonces ambos aspectos - tarifas y contingencias- delinearán el abastecimiento de las comunidades, ya no desde la distribución equitativa, sino desde la participación, generación de oportunidades, formación de capacidades y asunción de responsabilidades (Gissi \& Soto, 2010). 
Sin embargo, los recursos hídricos privados tienden a acentuar las asimetrías económicas entre pueblos originarios y urbes residenciales, excluyendo a los sectores migrantes. Si se adoptan como bienes públicos, entonces generarán un desbalance entre oferta y demanda que obligará al Estado a subsidiar a quienes no pueden costear el valor del agua. Por consiguiente, si se asumen como bienes comunes, el sistema moral de confianza, empatía, compromiso y solidaridad desplazará el valor del precio unitario del agua (Markowitz, 2012).

Las problemáticas hídricas globales y locales comparten el desbalance que supone el consumo per cápita y la disponibilidad. En esta relación asimétrica, el sistema de cobro restablece el equilibrio, pero a medida que se intensifican las diferencias entre quienes pagan con subsidios y aquellos que pueden costear su excesivo costo (León, 2013). La administración de los recursos y servicios hídricos en México, Distrito Federal, está indicada por un sistema de tarifas que se han ajustado conforme la disponibilidad hídrica pasó de 300 litros diarios por persona con un costo unitario de 0,25 pesos en 1950, a 120 litros diarios per cápita en el año 2000 cuando alcanzó un promedio de 50 pesos por volumen de consumo bimestral (Conagua, 2008).

El desequilibrio entre el volumen disponible y el consumo de agua generó un sistema de cobro en México que varía en función de la región, aunque por su grado de densidad poblacional la problemática se concentra en la capital de México.

Precisamente, la problemática hídrica local se puede inferir del incremento sustancial en el cobro de los servicios hídricos, en un periodo de quince años el precio unitario del agua aumentó un $400 \%$, implicando la exclusión de sectores que ingresan menos de dos dólares al día y frente a la pérdida de poder adquisitivo del salario que se devaluó en un $200 \%$.
El panorama económico de la disponibilidad hídrica en referencia al consumo humano resalta los conflictos derivados de la política de abastecimiento y cobro local. Las diferencias entre quienes gobiernan y establecen sistemas tarifarios discrecionales y quienes consumen el agua en función de la información diseminada en los medios de comunicación. Es así como una propaganda de escasez genera el ahorro del recurso, pero una difusión de abastecimiento inequitativo entre los residentes propicia un dispendio. Por consiguiente, es menester analizar la dimensión sociopolítica del sistema de abastecimiento.

\section{Escenarios políticos de la gobernanza de los servicios hídricos}

Es menester plantear que los recursos hídricos, de acuerdo con los marcos políticos, son recursos sociopolíticos. Esto es así porque un recurso supone la administración consensuada para el bien común, la salud colectiva o el desarrollo local sustentable (García et al., 2015). En este sentido, el agua ya no es solo un recurso que pueda ser privado, público o común, sino más bien -en virtud de que las capacidades de las generaciones en el futuro dependen de una disponibilidad mínima de agua-, un recurso sociopolítico, un instrumento de gestión que los sectores vulnerables, marginados o excluidos tendrán a bien negociar con las autoridades a fin de poder garantizar las necesidades de sus descendientes (Kalantari \& Asadi, 2010).

En el rubro de los conflictos, los grupos marginados son encauzados por los actores políticos a participar en función de la oferta y demanda de agua local. Se trata de un sistema de tandeo en el que el volumen de distribución hídrica se realiza conforme la participación civil en la contienda electoral y la promoción del partido político o candidato a puesto popular (García et al., 2014). En este sentido, el agua es un recurso sociopolítico, un instrumento de gestión, conflicto, consenso, administración y responsabilidad social, pero al ser un instrumento de gestión de desarrollo endógeno incentiva la 
competencia sociopolítica, que consiste en el apoyo a candidatos que ofrecen regularizar el sistema de tandeo más que administrar el agua, de tal modo que garantice la sustentabilidad y no la lucha entre los sectores marginados.

En el marco de los servicios hídricos, enaltece un proceso interno de la gobernabilidad conocido como gobernanza que, a diferencia de la rectoría del Estado en materia de administración de recursos y servicios públicos, consiste en la emergencia de propuestas civiles, debates y consensos de responsabilidad social.

La teoría de la gobernanza de los servicios hídricos no solo estriba en la relación equitativa entre autoridades y ciudadanos, sino también en la emergencia de estilos de vida austeros que indican la respuesta de la sociedad civil a la administración gubernamental, tal proceso se ha gestado en escenarios políticos, autoritarios y democráticos (véanse figuras 1, 2 y 3 ).

\section{Figura 1}

Escenarios políticos de la gobernanza de los servicios hídricos

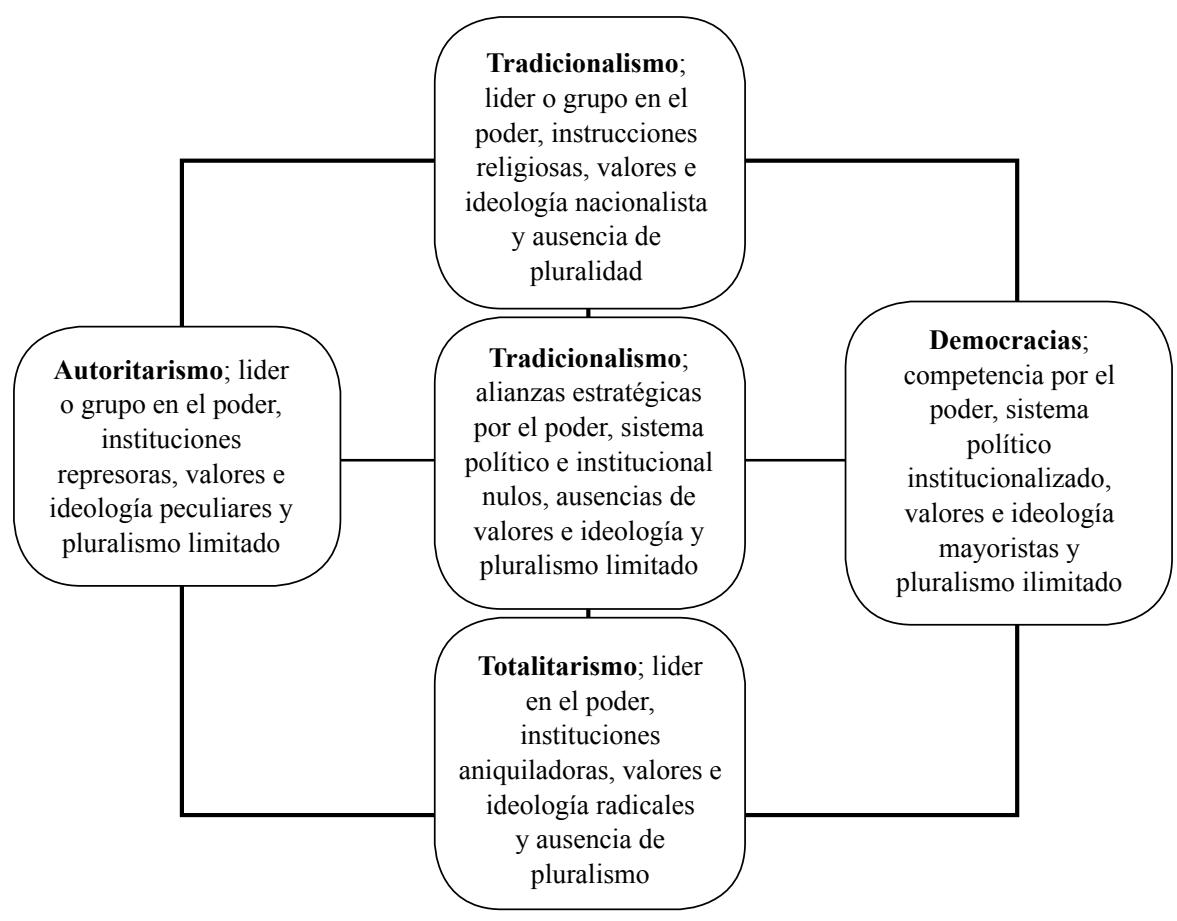

Fuente: García et al., 2014, p. 197.

La gobernanza de los servicios hídricos en relación con los sistemas políticos, se gesta en los autoritarismos y totalitarismos porque en estos regímenes las libertades se supeditan a la rectoría del Estado, garante de la seguridad territorial y sus recursos.

En los sistemas autoritarios y totalitarios, el agua es parte de un territorio y como tal la resguarda el Estado absolutista, pero a diferencia de los regímenes tradicionales, transitorios o democráticos, las comunidades no desarrollan un sentido de pertenencia, ni representación social que legitime una distribución del agua en las comunidades sin importar sus identidades.

Sin embargo, los sistemas coercitivos de la libertad exacerban propuestas civiles, en ese sentido es que los autoritarismos y totalitarismos generan la gobernanza, pero sobre 
todo propician que las comunidades construyan un sentido de pertenencia al entorno, ya que la pérdida de rectoría incrementa el etnocentrismo de las comunidades.

Figura 2

Escenarios autoritarios en torno a la gobernanza de los servicios hídricos

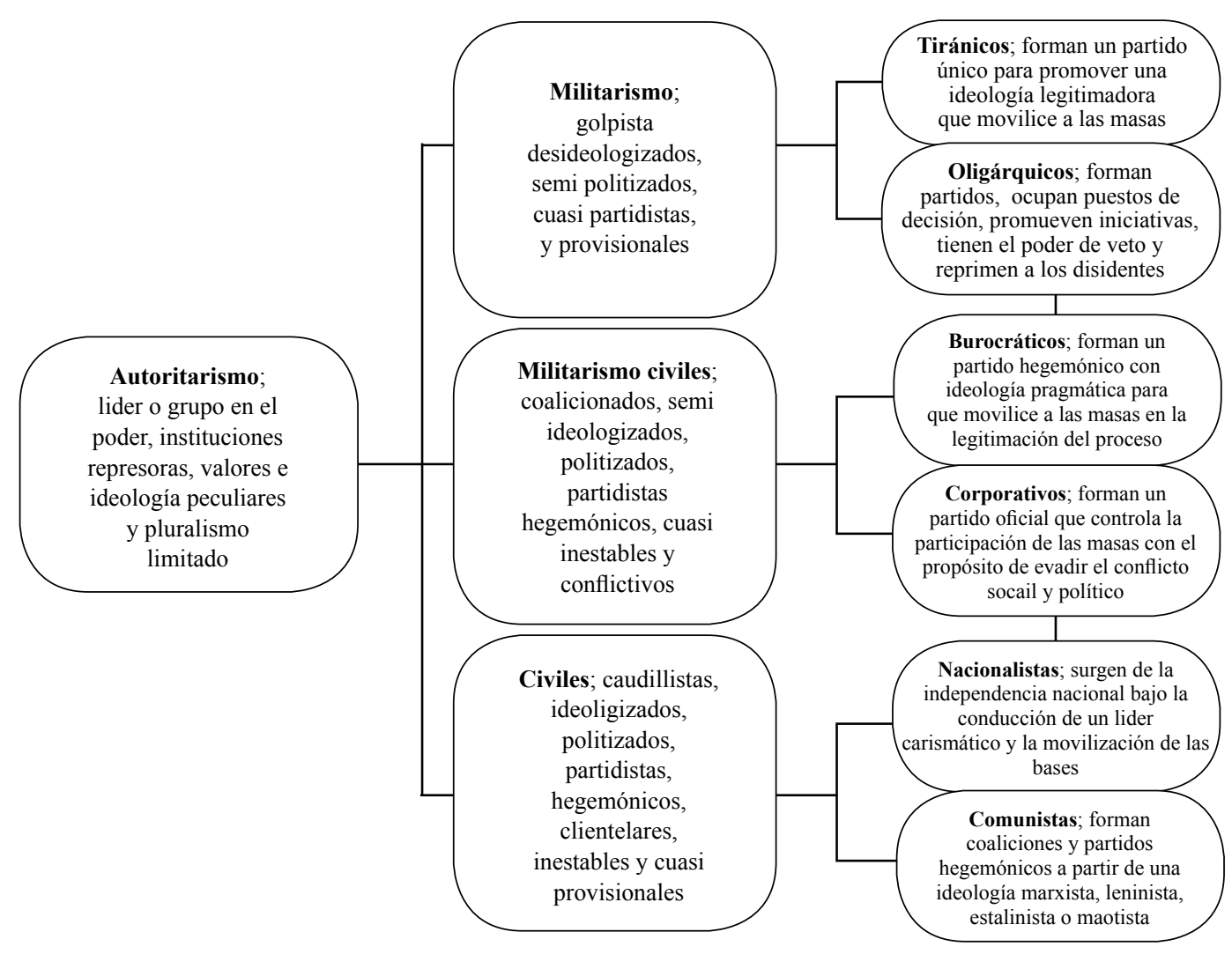

Fuente: García et al., 2014, p. 199.

En las instancias pretorianas o civiles, los autoritarismos son sistemas de gobernanza que acentúan los estereotipos hacia las autoridades y legitiman las diferencias entre los sectores con respecto a la distribución asimétrica de los recursos.

Empero, el sentimiento de comunidad y la representación social de abundancia o escasez del agua, son factores de disidencia que se reducen a su mínima expresión luego de que han sido legitimadas las asimetrías entre los grupos con abasto regular e irregular.

Por consiguiente, la elección de un grupo supone la administración del agua. La partici- pación civil se gesta en el apoyo o disidencia de quienes administran los recursos naturales, quienes gestionan el abastecimiento, quienes controlan la reutilización o tratamiento de aguas residuales y quienes fomentan el desarrollo local.

En estos escenarios, la gobernanza emerge como un modo de gestión que legitimará diferencias en torno al uso del agua, derechos de gestión y administración de residuos. Se trata de un sistema político en el que los actores dirimen sus diferencias, establecen acuerdos y emiten reglas de consumo. 
Figura 3

Escenarios democráticos en torno a la gobernanza de los servicios hídricos

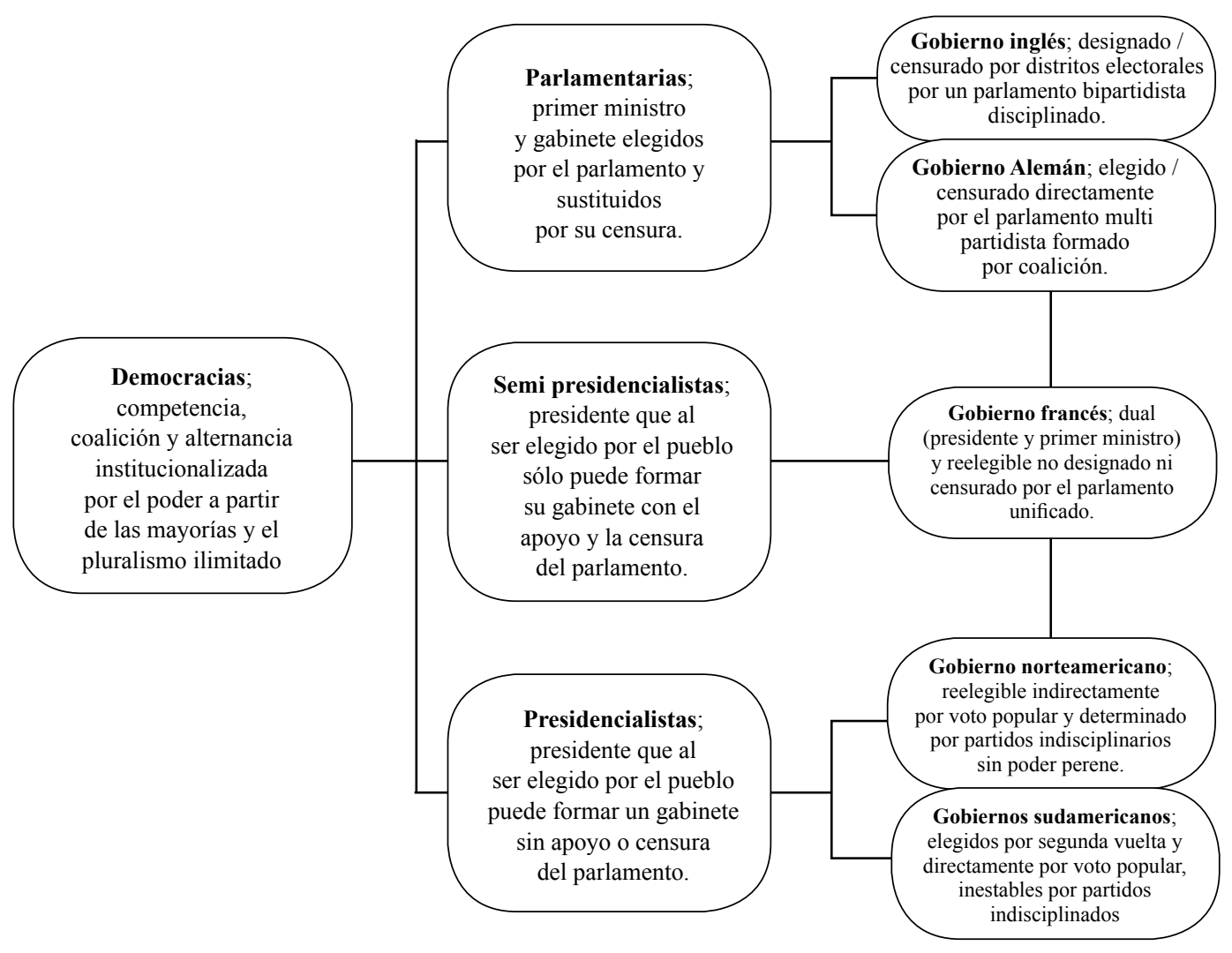

Fuente: García et al., 2014, p. 202.

Al contrario de los regímenes autoritarios, en los sistemas democráticos la administración hídrica supone el establecimiento de una agenda a partir de la diseminación informativa de los conflictos entre los grupos vulnerables, marginados y excluidos.

En las democracias parlamentarias el agua es un tema central, ya que las tarifas, subsidios y subvenciones se reparten entre quienes representan a las comunidades. En el sistema presidencial, el poder de iniciativa y veto, regula los conflictos hídricos y las disputas entre los usuarios del servicio de agua potable.

En el marco de la transformación del Estado y la burocracia, la emergencia de la participación ciudadana plantea que la gobernanza es un sistema administrativo en el que priman dos actores: gobernantes y gobernados en función de grado de conformidad o innovación.

En el primer caso, la gestión está determinada por la dominación y el control social a través del poder político diseminado sobre las esferas civiles (Abramo, 2012). En este sentido, el consenso se establece a partir de la coerción de la acción colectiva y la movilización social expuesta en los medios de comunicación como los obstáculos para la construcción de la paz pública, los acuerdos y convenios que sustentarán reformas estructurales.

Por su parte, la gobernanza por la vía de la innovación sugiere la participación de la ciudadanía como actor fundamental en la 
ejecución y diseño de las políticas y programas socioambientales. En este proceso, la influencia es el instrumento por medio del cual se disponen los temas de debate, se gestan los acuerdos y se orientan las oportunidades, capacidades y responsabilidades civiles en torno al diseño de las estrategias de inclusión y derecho a los recursos y servicios urbanos.

En el caso de la gobernanza de los recursos y servicios hídricos, los conflictos que afloran por el desbalance entre disponibilidad y consumo se dan en escenarios de escasez y desabastecimiento, frente a los que las políticas municipales establecen sistemas de tandeo y cobro a fin de reducir las diferencias entre gobernantes y gobernados.

Según el grado de abastecimiento y costo del precio unitario del agua, los conflictos hídricos adquieren una dimensión inequitativa que puede escalar, hasta un punto en que autoridades y usuarios acuerdan desabastecer o comprometer las capacidades de futuras generaciones. Antes bien, la inequidad distributiva puede aminorarse con los conflictos que supone la disuasión social alrededor del quebrantamiento de reglamentos entre usuarios que comparten los recursos, o bien, los subsidios que persuaden a los sectores más radicales a descartar actos violentos tales como cierres de avenidas, secuestros de pipas o boicots a las instalaciones hidráulicas.

El incremento de tarifas no necesariamente corresponde al costo real de los servicios hídricos (Martínez \& Montero, 2010), sino más bien deriva de estrategias disuasivas del consumo (Martínez \& Montero, 2011), pero también es instrumento de subsidio de los sectores identificados como más radicales por su capacidad de movilización y confrontación con las autoridades (Acosta, 2010). Relacionadas con las subvenciones, las condonaciones son una herramienta que posibilita la paz pública y posterior renegociación con aquellos sectores vulnerables, marginados o excluidos que destinan hasta el $20 \%$ de sus ingresos para el abastecimiento de agua.

Resultado de los conflictos inequitativos, los monopolios de las unidades de abastecimiento que se conocen como pipas exacerban las diferencias entre quienes tienen una provisión regular y pagan un precio ligeramente superior $\mathrm{y}$ quienes se someten al tandeo y están expuestos al incremento desproporcional del precio unitario. En este escenario, los estilos de vida son más coercitivos porque existe una doble exclusión posterior a la política de tandeo: el acaparamiento de agua en zonas de alta marginalidad.

En contraste, la gobernanza que se gestaría desde los conflictos y acuerdos muestra posibilidades de gestión, consumo y tratamiento de aguas residuales en tanto que existen los mecanismos para la participación ciudadana y la negociación con sus autoridades locales respecto al costo del servicio y reciclaje (Manríquez \& Montero, 2011). Se trata de estilos de vida consensuales en los que los usuarios pagan un precio superior al que supone el servicio, pero tienen la garantía de un abastecimiento regular, aunque esta modalidad administrativa puede derivar en monopolios de los sectores organizados sobre las zonas periféricas que sufrirían el desabastecimiento de agua.

En cuanto a la dimensión relativa a la disuasión como instrumento de gobernanza hídrica, estaría indicada por la dominación de grupos gestores que garantizan el abastecimiento y mantenimiento del servicio de agua potable a partir de incrementar exponencialmente las tarifas, o bien, suprimir los subsidios o condonaciones (Carosio, 2010). Es un escenario en el que los medios de comunicación fijan los temas de discusión y legitiman las políticas tarifarias ante la opinión pública (Duerden \& Witt, 2010). Incluso, en este modelo de gobernanza el establecimiento de una agenda pública es factor preponderante para la exclusión de opiniones a favor del cooperativismo (Corral \& Domínguez, 2011). 
La dimensión relativa a la persuasión consiste en la promoción de valores cívicos ambientales que orienten el ahorro de agua, pero sin cuestionar las asimetrías entre el consumo de la agroindustria y las residencias. Se trata de una estrategia precautoria para los desastres naturalespropiciadosporsequíasoinundaciones, que devendrían en una inestabilidad social y la subsecuente competencia por los recursos hídricos. La persuasión busca promover estilos de vida favorables a la conservación del agua, aunque las tarifas se aumentan, no generan una inflación en la economía local.

No obstante, la gestión y la administración del agua como políticas públicas, son inherentes una "violencia del Estado" que supone el gobierno de necesidades básicas consideradas como iusnaturalistas o violentas en su esencia. Es decir, los usuarios descargan la responsabilidad del abastecimiento al Estado, pero se resisten a una vida austera. En este sentido, los desacuerdos, desconocimiento de convenios, ambivalencias y hostilidad son indicativas de escenarios de conflictos entre los usuarios y las autoridades locales.

La violencia invisible que implican los discursos xenófobos acerca de las minorías vulnerables, marginadas o excluidas parece incentivar políticas de subsidios que prevengan movilizaciones o acciones violentas, pero también legitiman los subsidios o condonaciones que las autoridades pueden orientar como reclutamiento de militantes (Malmod, 2011).

En contraste, la violencia por consenso conlleva no solo la participación de todos los sectores, sino además el ejercicio del poder de la mayoría frente a los usos y costumbres de comunidades migrantes (Barkin \& Lemus, 2012). Se trata de un escenario en el que las tarifas regulan las diferencias entre sectores residenciales, oriundos o migrantes a partir de asignar un precio unitario según el ingreso per cápita, o bien, el grado de desarrollo humano.
Ahora, la violencia en materia de abastecimiento de agua y políticas de tandeo se dirige a grupos que cierran avenidas, se confrontan con autoridades, secuestran pipas o intervienen el suministro municipal. Es una política de combate frontal a la delincuencia que se apropia de las instalaciones bajo el emblema de los derechos a la gratuidad del agua, pero que establece redes de comercio del líquido en las zonas con menor disponibilidad y abastecimiento, propiciando que estos usuarios destinen hasta un $20 \%$ de sus ingresos en la compra del agua.

Por último, la administración de los recursos hídricos tendría una dimensión ambivalente en aquellas zonas y sectores debido a su desabastecimiento y bajo costo del servicio. Precisamente, su carácter ambivalente consiste en que la cantidad y calidad del agua corresponden a su bajo costo y consumo, por ello son colonias que viven en estrés constante porque el Estado ni les incrementa el costo ni les mejora el servicio (Montalbetti \& Chamarro, 2010).

En resumen, la gobernanza de los recursos hídricos tiene cuatro dimensiones: relaciones entre sectores, grado de abastecimiento, precio unitario del suministro y tratamiento de agua. Cada dimensión consiste en una administración considerando niveles de conflictos y violencia previsibles por la escasez, desabastecimiento y costo.

\section{Escenarios ambientales y sanitarios de la gobernanza de los servicios hídricos}

Los escenarios ambientales de los recursos sociopolíticos advierten que la disponibilidad de agua y su administración consensuada dependen de los efectos del cambio climático sobre la salud pública ambiental, la calidad de vida y el bienestar social (véase figura 4). En los países desarrollados su volumen per cápita se orienta al uso residencial e industrial, mientras que la mayor 
parte de la demanda se dirige a la agricultura en los países emergentes (Nozica, 2011).

México emplea mayor volumen hídrico que Brasil, España y Estados Unidos para la agricultura, pero su uso residencial solo es inferior al de Brasil. Respecto al volumen de agua con destino a la industria, México ocupa el último sitio, pero a diferencia de Estados Unidos en donde se recicla, su uso intensivo no tiene un tratamiento (McCright \& Riley, 2011).

No obstante que el sector agroindustrial está sujeto a una evaluación de consumo, los datos relativos al uso residencial varían en función de las estimaciones institucionales con respecto a los organismos internacionales. $\mathrm{La}$ Organización para la Cooperación y el Desa- rrollo Económico ha recopilado los datos que las instituciones o ministerios encargados del abastecimiento regional y local emiten en cada uno de sus países miembros, estableciendo un índice tarifario de acuerdo con la disponibilidad y el uso per cápita. En este ranking, México ocupa el último lugar y Noruega el primer sitio.

En la medida en que la escasez de los recursos hídricos se acentúa y el abastecimiento de agua se reduce a su mínima expresión, los sectores excluidos adoptan estilos de vida austeros que previenen contingencias por la carencia y conflictos por la administración del agua, el incremento de tarifas o la discrecionalidad gubernamental en torno al subsidio o condonación de cuotas (McCright, 2010).

Figura 4

Escenarios ambientales de la gobernanza de los servicios hídricos

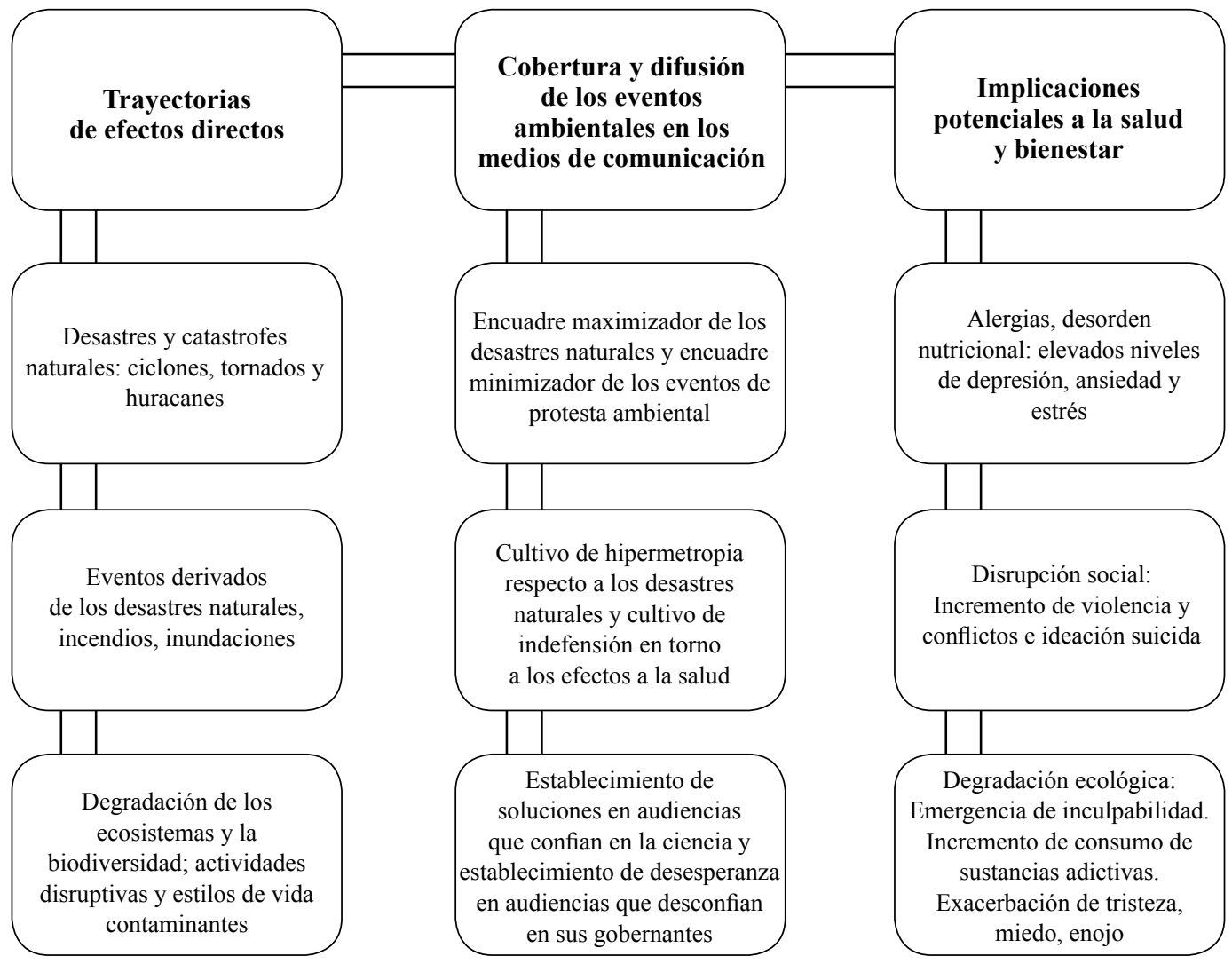

Fuente: Elaboración propia. 
El estudio de Londoño y Cardona (2011) acerca de las oportunidades y los recursos para el desarrollo humano, concibe a la naturaleza como proveedora de las herramientas para la formación de capacidades que incentiven la conservación, pero ajustada a las expectativas y necesidades de desarrollo.
En el caso de los escenarios sanitarios, los recursos hídricos asumidos como sociopolíticos, son instrumentos de presión social para la implementación de programas preventivos $\mathrm{y}$ promoción de la salud, aunque también se generan comportamientos asociados con los riesgos a la salud que implican el consumo de cuencas contaminadas, cuerpos de agua sobreexplotados o tomas clandestinas (véase figura 5).

Figura 5

Escenarios sanitarios

de la gobernanza de los servicios hídricos

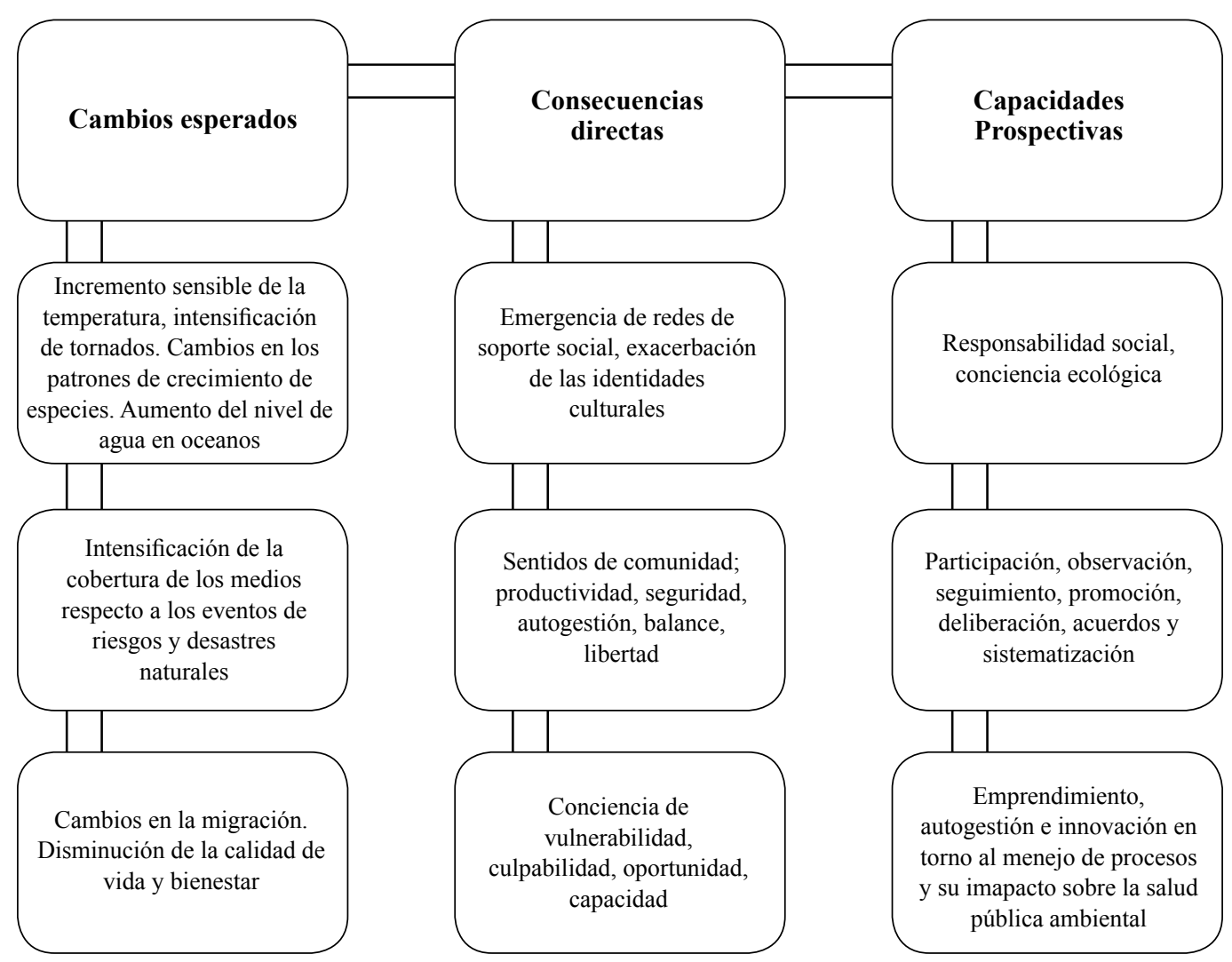

Fuente: Elaboración propia.

Por último, Moreno (2013) sostiene que los esquemas de cooperación entre naciones, en materia de saneamiento hídrico, son condicionantes para el desarrollo de tecnología y generación de conocimientos, que permiten transformar los recursos en oportunidades de elección y acción transgeneracional. Reguladas por bonos de carbono, las actividades humanas accederían a convenios de reducción de emisiones para poder garantizar su sustentabilidad.

\section{Escenarios sociales de la gobernanza de los recursos hídricos}

Los marcos teóricos y conceptuales sociológicos y psicológicos, así como las eviden- 
cias empíricas advierten que la gobernanza es un sistema de administración de grados de conflictos y niveles de violencia, generados por el desbalance entre disponibilidad y consumo que el sistema de tandeo y cobro locales no han podido estabilizar y más bien exacerban la exclusión hídrica.

Desde el enfoque sociológico, las diferencias entre los grupos disidentes y simpatizantes del incremento de tarifas y el tandeo del suministro de agua se legitiman y diseminan entre los integrantes de los grupos mediante la membresía. El habitus explica la transferencia de acciones concretas de ahorro de agua, optimización y reutilización que legitiman el desabastecimiento y el tandeo en los sectores excluidos (Touguinha \& Pato, 2011).
No obstante, el habitus se genera en espacios o campos de poder e influencia. En este sentido, quienes se organizan para administrar un cuerpo de agua aprenden a negociar con otros grupos la distribución del fluido a partir de los derechos a los acuíferos. En el proceso de formación de habitus en contextos de austeridad, los capitales resultan fundamentales para el fortalecimiento de los estilos de vida frugales, aunque también legitiman la política de abastecimiento local.

Las redes colaborativas de gestión, acaparamiento y distribución de agua en una localidad suponen habilidades y capacidades que se dan a partir de la rectoría del Estado en materia de oportunidades de extracción de agua, y de la responsabilidad social que se espera al considerar a los recursos hídricos como factores sociopolíticos de desarrollo local (véase Figura 6).

\section{Figura 6}

\section{Escenarios sociales de la gobernanza de los servicios hídricos}

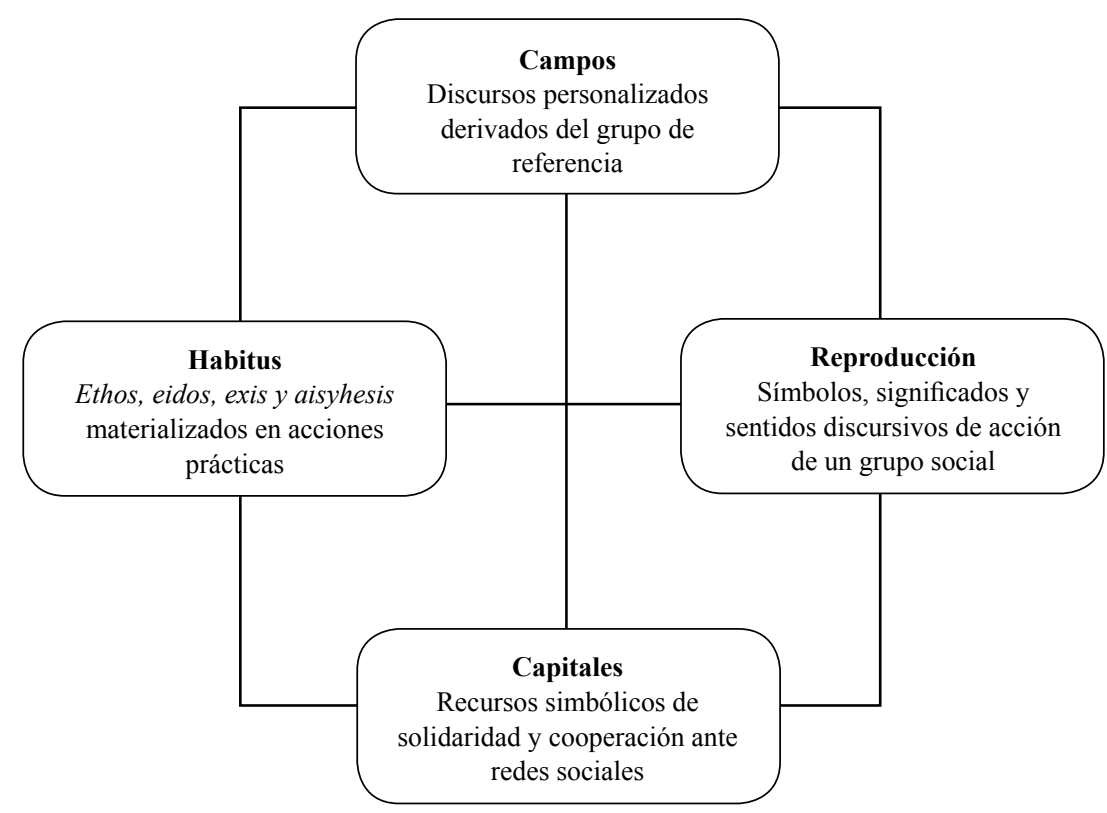

Fuente: Elaboración propia

\section{Escenarios psicológicos de la gober- nanza de los servicios hídricos}

Los escenarios sociales resultan insuficientes para entender la administración consensuada de los servicios hídricos en regímenes de Gobierno y formas de Estado autoritarias y democráticas que legitiman sus políticas tarifarias, subsidios y condonaciones mediante una agenda pública (García, 
2013). Se trata de temas establecidos en los medios de comunicación con la finalidad de influir en la opinión pública respecto al cui- dado del agua, el pago de adeudos del servicio de agua potable o la denuncia de fugas (véase Figura 7).

Figura 7

Escenarios psicosociales de la gobernanza de los servicios hídricos

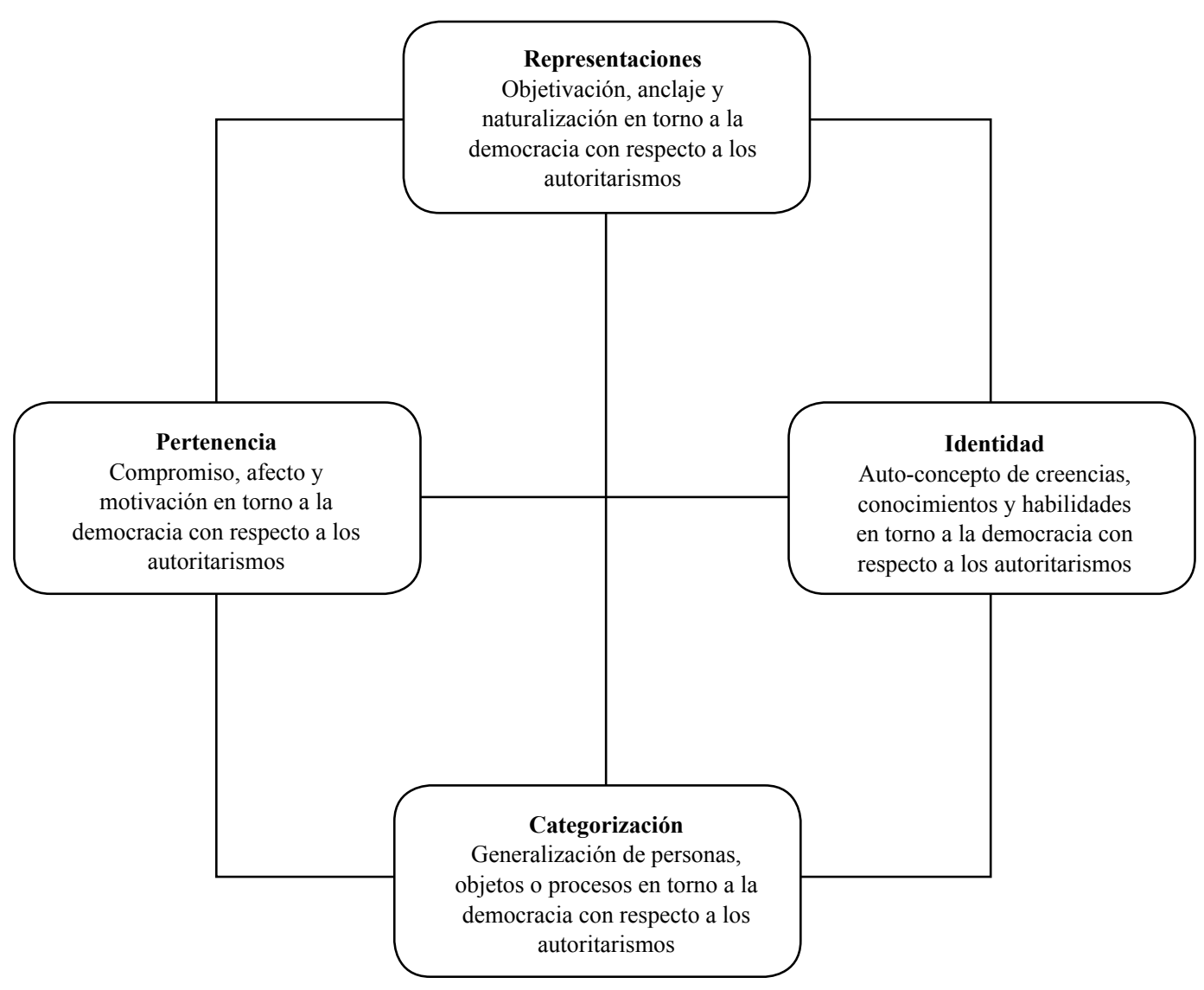

Fuente: Elaboración propia.

Los medios de comunicación al enfatizar los conflictos entre las autoridades locales y los usuarios del servicio público de agua potable, influyen en la opinión pública (Leff, 2011). En este sentido, las teorías de sistemas, tecnológicas, informacionales y comunicacionales han avanzado en la hipótesis del establecimiento de la agenda -a partir del análisis del encuadre de los hechos para develar como productores de información a los medios de comunicación-, como mediadora de la opinión ciudadana y como objetivo de las iniciativas políticas de ley (Carreón, Hernández, \& García, 2014).
Los medios de comunicación presentan los conflictos como asuntos centrales de la problemática hídrica, pues responsabilizan a las autoridades por la ineficiencia de las tarifas y exponen a los cierres de avenidas, boicots a instalaciones o secuestros de pipas como evidencias de ingobernabilidad que inhiben el desarrollo sustentable local (Carreón et al., 2014).

En la revisión de Jaén y Barbudo (2010) se sostiene que el desarrollo humano se gesta desde valores antropocéntricos que determina- 
rán la socialización con los recursos naturales y los servicios municipales a través de representaciones sociopolíticas de conformidad, obediencia, indignación o violencia.

Un efecto del establecimiento de la agenda es la polarización de las audiencias. Se trata de grupos que adhieren sus expectativas a las políticas públicas versus grupos disidentes de los programas de tandeo, sistemas de cobro, subsidios o condonaciones (García, 2012). Tales diferencias se fundamentan en el sentido de pertenencia que los recursos naturales en general y los recursos hídricos en particular, generan en un escenario local de desarrollo sustentable (Lucca, 2010).

De este modo, el sentido de comunidad suscita estereotipos a partir de los cuales se esperan dirimir los conflictos por el manejo de acuíferos, distribución mediante pipas o tomas de abastecimiento central. La categorización no solo distingue los grupos, sino además justifica tales diferencias con respecto a los derechos por el uso de los recursos naturales y servicios públicos (Seacat \& Northrup, 2010).

Empero, el sentido de pertenencia a un entorno y el apego a un lugar de origen se orientan por símbolos y significados que en un contexto histórico resaltan por su importancia en el desarrollo endógeno. El sentido de pertenencia se simboliza a menudo con los recursos naturales que permitirán el progreso de un grupo en un espacio determinado. La categorización social puntualiza el sentido de pertenencia y administración de los recursos que emanan de los espacios considerados como símbolos de la comunidad. En ambos casos, sentido de pertenencia y categorización, existe una relación que vincula el núcleo central con las representaciones periféricas del agua, sus usos y costumbres (Klôckner \& Blôbaum, 2010).

En la representación periférica y el núcleo central, se develan procesos sociopolíticos que transforman a los recursos en general y al agua en particular, en símbolos de poder e influencia entre los conflictos de grupos que pretenden su gestión o autogestión.

La identidad que es la culminación de los factores psicosociales, consiste en un conglomerado de decisiones y elecciones no siempre racionales y más afectivas, en las que el individuo que necesita de agua se decanta por la acción de un grupo con respecto al abastecimiento del líquido. Así, la identidad hídrica sociopolítica refiere a los actores de cooperación y solidaridad entre colectivos que sufren el tandeo versus grupos que tienen un abastecimiento regular de agua (Milfont \& Duckitt, 2010).

Los marcos teóricos y conceptuales de la psicología de la sustentabilidad, sostienen que la gobernanza de los recursos hídricos se gestaría y gestionaría apelando a la racionalidad, la planificación y la sistematización del ahorro y reutilización del agua. El sistema de cobro ha sido cuestionado por la aproximación psicosocial, la cual advierte una serie de conflictos derivados del servicio de agua potable y las tarifas correspondientes (Leff, 2010).

Para la teoría de la acción razonada las actitudes son mediadoras del efecto de las creencias sobre las intenciones y los comportamientos (Ajzen \& Fishbein, 1974). Un incremento en las creencias aumenta las disposiciones hacia decisiones y acciones específicas y deliberadas. Se trata de un proceso que va de lo general en cuanto a creencias hacia lo particular en cuanto a intenciones $\mathrm{y}$ acciones. No obstante, el poder predictivo de las creencias generales está acotado por la especificidad y unidimensionalidad de las actitudes. Dado que las actitudes transmiten el efecto de las creencias, delimitan sus indicadores en disposiciones probables de llevarse a cabo (véase figura 8). 
Figura 8

Escenarios psicopolíticos

de la gobernanza de los servicios hídricos

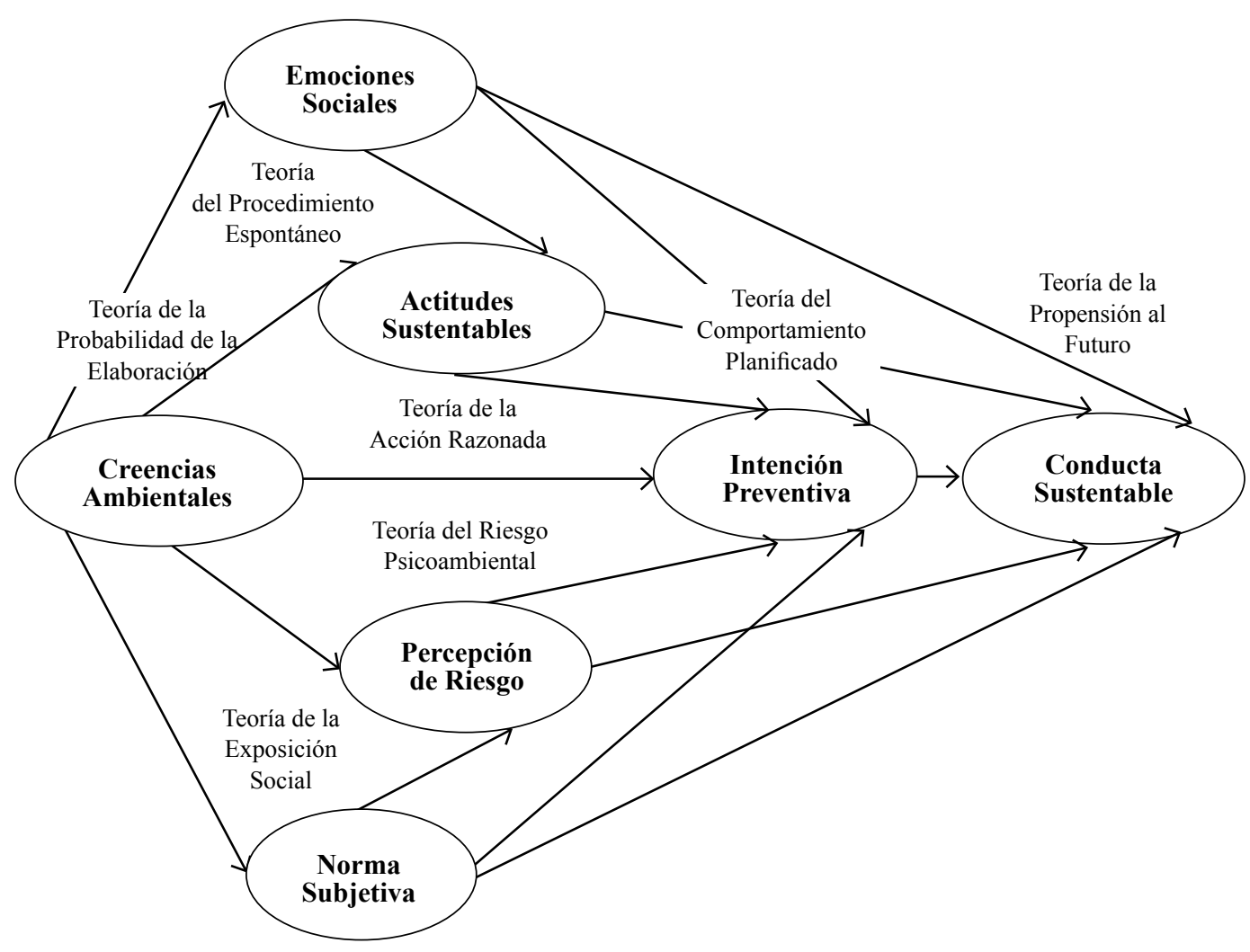

Fuente: Elaboración propia.

La teoría de la conducta planificada informa que el efecto de las creencias sobre el comportamiento está mediado por actitudes y percepciones de control. Ante una situación o evento contingente, la percepción de control acrecienta su poder predictivo de las intenciones y los comportamientos si y solo si interactúa con disposiciones específicas. En la medida en que la percepción de control disminuye, su relación con las actitudes hace predecible un efecto espurio en las decisiones. Necesariamente, el proceso deliberado y planificado de la toma de decisiones e implementación de estrategias requiere de una percepción de control consistente con las disposiciones hacia el objeto (Ajzen, 1991).
Si la gobernanza de los recursos y servicios hídricos es una estrategia de administración según los grados de conflicto y violencia que se gestarían a partir de cuatro dimensiones de análisis que van de la inequidad hasta el consenso, entonces los estudios relativos a la construcción de acuerdos o resolución de asimetrías, versan sobre aquellos procesos inherentes a la gestión, que por su grado de participación civil estarían cercanos a la democratización de los servicios municipales, pero resalta su desvinculación entre los sectores residenciales, pueblos originarios y zonas periurbanas migrantes (véase figura 9). 


\section{Figura 9}

Escenarios investigativos

de la gobernanza de los servicios hídricos

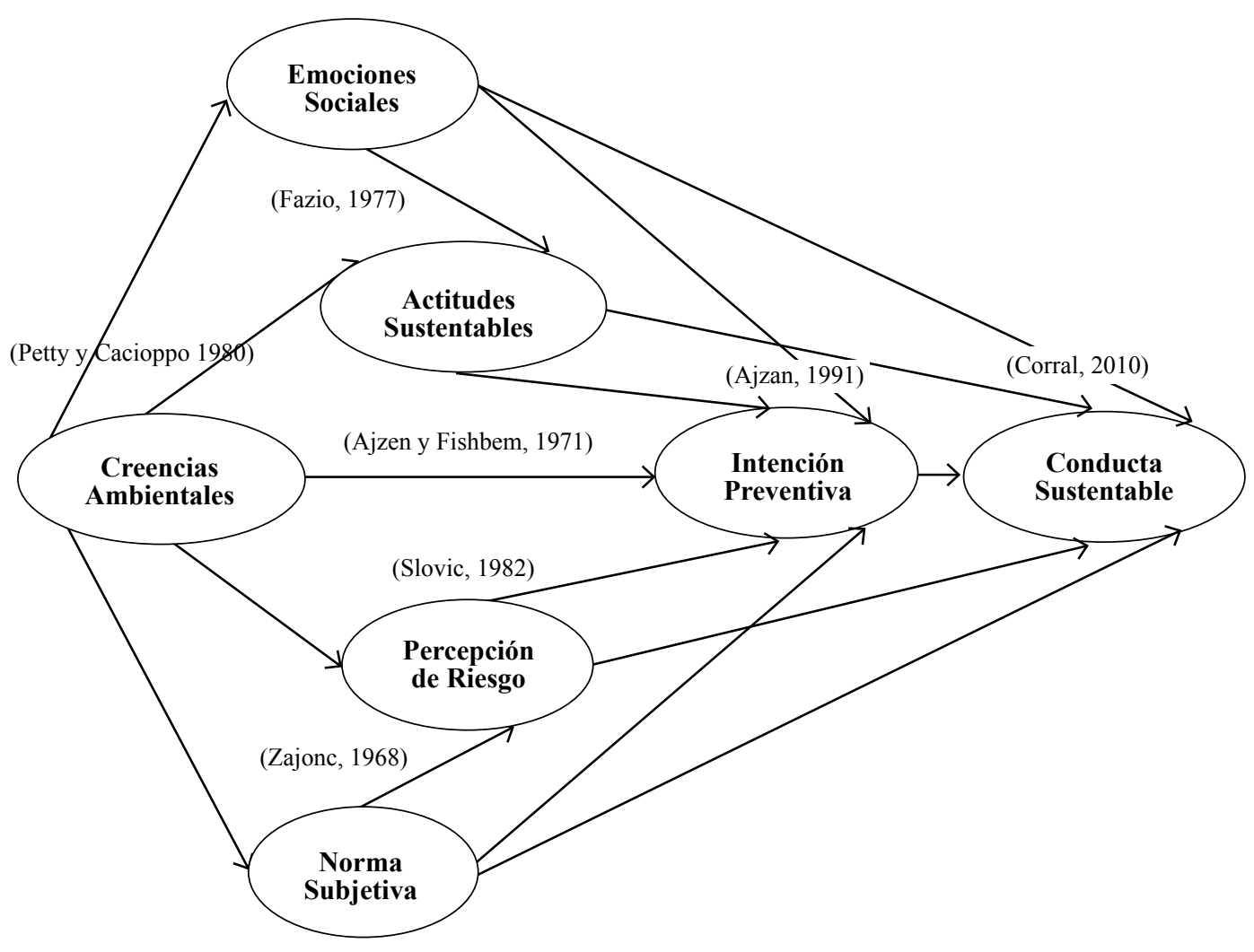

Fuente: Elaboración propia.

La autogestión es un fenómeno social que explicaría la acción colectiva y movilización social, en torno a sequías o inundaciones que al generar un desabastecimiento obligarían a la organización civil; también supone la oportunidad de comercializar con un producto de primera necesidad a través del acaparamiento del agua (Blunda, 2010). En este sentido, el almacenamiento estaría comprometido, ya que el sistema de tandeo funciona según un régimen periódico que se complementa con el almacenamiento de agua más que por su reutilización, tratamiento o captación pluvial, indicadores de propensión al futuro o comportamiento orientado a la sustentabilidad (Corral, 2010).

Precisamente, es en esta fase en la que el sistema de tandeo pierde relevancia, pues el almacenamiento no corresponde con el uso dosificado del agua, que es un estilo de vida guiado por valores ecoperiféricos más que antropocentristas, como es el caso del acaparamiento (Groot \& Steg, 2010).

Por su parte, la reutilización tendría nexo con la dosificación en tanto que una vez utilizada el agua de manera austera, un nuevo uso de la misma supondría una alternativa ante la ineficiencia del tandeo, pero la reutilización más bien es parte del emprendimiento que supone la comercialización del agua, independiente de su calidad y cantidad (Behancourth, 2010).

La cotización del servicio de pipas, una vez que el agua se empleó y que ahora se pretende vender como de primer uso, o bien, 
se advierte que ya ha sido tratada, filtrada o procesada, estaría relacionada con las formas cooperativas en las que las pipas o vendedores del agua se organizan, aunque el tratamiento suponga un procesamiento complejo del agua que el usuario estaría dispuesto a costear antes de organizar una protesta colectiva ambiental (Jiménez \& Lafuente, 2010).

La conducta sustentable que emerge como producto de una administración consensuada de los recursos y servicios hídricos, es un factor preponderante en la predicción de escenarios de conflicto y violencia a medida que los niveles de acción favorable al medioambiente disminuyen, pero anticipa escenarios de pacificación y cooperación en los momentos en que los niveles de participación se incrementan o las acciones de dosificación y reutilización se intensifican (Bertoni \& López, 2010).

Sin embargo, un modelo de gobernanza requeriría de dimensiones más vinculantes que anticipen la reapropiación de la naturaleza y no solo su conservación por motivos económicos o políticos, sino su restauración por biofilia o ecoperiferismo como factores ideológicos de res- peto y cuidado permanentes hacia el entorno y que a su vez, indicarían una cultura ambiental e hídrica transgeneracional (Flores \& Parra, 2011).

Desde un enfoque psicológico, los estudios de los recursos sociopolíticos se han enfocado en su conceptualización, formación, activación, accesibilidad, estructura, función, predicción, cambio, inoculación, identidad y ambivalencia (Ajzen, 2001). Los recursos sociopolíticos han sido definidos a partir de dimensiones afectivas y racionales. Ambas dimensiones son el resultado de experiencias y expectativas (Ajzen, 2002).

Esto implica su estructura: unidimensional o multidimensional que se configura en factores exógenos y endógenos (Schwartz \& Bohner, 2001). Es decir, cuando los recursos sociopolíticos activan decisiones y comportamientos causan un proceso periférico, emotivo, espontáneo, heurístico y ambivalente (Guering, 1994). En contraste, cuando los recursos sociopolíticos transmiten los efectos de valores y creencias sobre las intenciones y acciones, son mediadores endógenos de un proceso central, racional, deliberado, planificado y sistemático (véase figura 10).

Figura 10

Escenarios psicológicos de la gobernanza de los servicios hídricos

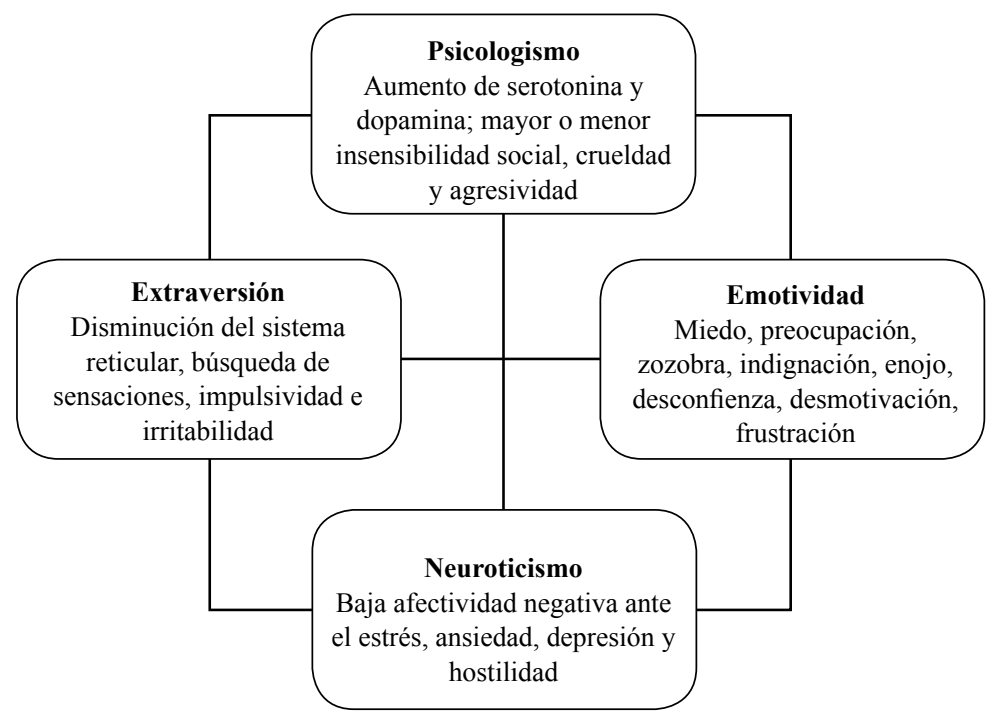

Fuente: Elaboración propia. 
La formación de recursos sociopolíticos iniciadesdecuatroprocesospsicológicosbásicos: extraversión, neuroticismo, psicologismo y emotividad, que indicarían niveles de ansiedad por la escasez y desabastecimiento de agua. Una vez activados estos síntomas sería posible anticipar los escenarios psicosociales.

Si los recursos sociopolíticos generan estados de ansiedad y emotividad que descentran la problemática de escasez y desabastecimiento del agua de los individuos y sus procesos racionales económicos, entonces los factores psicosociales ubicarán los conflictos por la administración del agua en los grupos conformistas versus innovadores (Quiroz, 2013). Los recursos sociopolíticos que inician como indicadores de ansiedad y emotividad psicológica, transitan por procesos psicosociales de pertenencia, categorización, representación e identidad, pero adquieren un sentido sociopolítico por la vía de los habitus, campos y capitales que legitiman la reproducción de la dominación social (Sharples, 2010).

\section{Consideraciones finales}

La comparación de los escenarios económicos, políticos, ambientales, sanitarios, sociales y psicológicos aportada en el presente trabajo se llevó a cabo a partir de extraer los temas difundidos en la literatura revisada. Es decir, se analizó el establecimiento de una agenda en materia de gobernanza de los recursos y servicios hídricos según la agenda fijada por la literatura seleccionada. Precisamente, ese es el límite del estudio documental expuesto.

Sin embargo, a diferencia de la agenda establecida por los medios de comunicación con respecto a la gobernanza de los recursos y servicios hídricos, la agenda de la literatura académica contrasta escenarios económicos, políticos, ambientales, sanitarios, sociales y psicológicos que coadyuvan a la reflexión, la discusión, el consenso y la responsabilidad entre los actores económicos, políticos, sociales y comunitarios.
La agenda de los medios se caracteriza por determinar una opinión emocional en audiencias que centran el problema en la administración pública de los recursos y servicios hídricos, $\mathrm{y}$ una opinión racional en audiencias que observan en los estilos de vida, los intereses de transnacionales y en la corrupción política, las barreras de la sustentabilidad hídrica.

El efecto de la agenda mediática en las audiencias consiste en el desarrollo de una lógica de verosimilitud que sustenta la opinión emocional, y en el desarrollo de una lógica de verificabilidad que sustenta la opinión racional. Ambas lógicas y opiniones, se transforman en posturas a favor y en contra de la administración consensuada de los recursos y servicios hídricos (gobernanza).

Son estos procesos los que la agenda académica resalta para reflexionar y proponer la discusión de la gobernanza -gestión y administración- de los recursos y servicios hídricos, siempre que estos se asuman como bienes transgeneracionales, porque si se asumen como privados, públicos o comunes se excluye a las futuras generaciones de especies animales y vegetales, entre las que se encuentra la humana, de la gestión y administración de acuíferos y demás cuerpos de agua para su desarrollo sustentable.

\section{Referencias}

Abramo, P. (2012). La ciudad com-fusa: mercado y producción de la estructura urbana en las grandes metrópolis latinoamericanas. Eure, 38(114), 35-69.

Acosta, A. (2010). Sólo imaginando otros mundos, se cambiará este. Reflexiones sobre el buen vivir. Sustentabilidades, 1(2), 10-28.

Acosta, J., \& Montero, M. (2001). Relación entre conducta proambiental y algunos componentes psicológicos en estudiantes mexicanos. Medio Ambiente y Comportamiento Humano, 2, 45-58. 
Aguilar, J. \& Valencia, A. (2005). Un modelo estructural de la disidencia política. En J. Manjarrez (coord.). Psicología social y cultura política (pp. 120-135). México: UAEMEX.

Ajzen, I. \& Fishbein, M. (1974). Factors influencing intentions and the intention behavior relation. Human Relations, 27, 1-15.

Ajzen, I. (2001). Nature and operation of attitudes. Annual Review Psychology, 52, 27-58.

Ajzen, I. (2002). Attitudes. En R. Fernandez B. (Ed.), Encyclopedia of Psychological Assessment (pp. 110-115). London: Sage Publications.

Barkin, D., \& Lemus, B. (2012). La economía ecológica solidaria. Una propuesta frente a nuestra crisis. Sustentabilidades, 3(5), 4-10.

Beck, A., Sinatra, G., \& Lombardi, D. (2013). Leveraging higher education instructor in the climate literacy effort: factors related to university faculty's propensity to teach climate change. International Journal of Climate Change Impacts and Responses, 4, 1-17.

Behancourth, L. (2010). Los consumidores ecológicos y el fomento de los mercados verdes; una alternativa hacia el bienestar espíritu, mente y salud a partir de la adopción de estilos de vida saludables. Eleuthera, 4, 193-210.

Bertoni, M., \& López, M. (2010). Valores y actitudes hacia la conservación de la reserva de la biosfera. Estudios y Perspectivas de Turismo, 19(5), 835-849.

Blunda, Y. (2010). Percepción de riesgo volcánico y conocimiento de los planes de emergencia en los alrededores del volcán Poas, Costa Rica. Revista Geológica de América Central, 43, 201-209.
Bustos, J. M., Flores, M., \& Andrade, P. (2004). Predicción de la conservación de agua a partir de factores socio cognitivos. Medio Ambiente y Comportamiento Humano, 5 , 53-70.

Carosio, A. (2010). La cultura del consumo contra la sustentabilidad de la vida. Sustentabilidades, 1(2), 50-61.

Carr, W., Patterson., M., Yung, L., \& Spencer, D. (2012). The faithful skeptics: evangelical religious belief and perception of climate change. JSRNC, 3, 276-299.

Carreón, J., Hernández, J., \& García, C. (2014). Análisis de notas de prensa respecto a condonaciones de pago por servicios hídricos. Doxa, 4(8), 134-152.

Carreón, J., Hernández, J., García, C., Rivera, B., \& Morales, M. (2014). Análisis de notas de prensa en torno al encuadre sociopolítico de tarifas hídricas. OBETS, 9(1), 7394. doi: 10.14198/OBETS2014.9.1.03.

Cerda, A. U., García, L. P., Díaz, M. M., Núñez, C. N., \& Rojas, J. M. (2007). Perl y Conducta Ambiental de los Estudiantes de la Universidad de Talca, Chile. Panorama Socioeconómico, 25(35), 148-159.

Comisión Nacional del Agua -[CONAGUA]. (2008). Informe anual de la situación del agua. México: Autor.

Comisión Nacional del Agua -[CONAGUA] (2012). Bancos de agua en México. México: Autor.

Consejo Nacional de Población -[CONAPO] (2010). Situación demográfica de México. México: Autor.

Cunsolo, A., Harper, S., Ford, J., Edge, V., Ladman, K., Houle, K., Blake, S., \& Wolfrey, C. 
(2013). "Climate change and mental health: an exploratory case study from Rigolet, Nunatsiavut, Canada". Climatic Change, 120(12), 255-270.

Corral, V. (2003). Situational and personal determinants of waste control practices in Northern Mexico: a study of reuse and recycling behaviors. Recourses, Conservation \& Recycling, 39, 265-281.

Corral, V. (2010). Psicología de la sustentabilidad. Un análisis de lo que nos hace proecológicos y prosociales. México: Trillas.

Corral, V., Bonnes, M., Tapia, C., Fraijo, B., Frias, M., \& Carrus, G. (2009). Correlates of pro-sustainable orientation the affinity towards diversity. Journal of Environmental Psychology, 29, 34-43.

Corral, V., \& Domínguez, R. (2011). El rol de los eventos antecedentes y consecuentes en la conducta sustentable. Revista Mexicana de Análisis de la Conducta, 37(2), 9-29. doi: 10.5514/rmac.v37.i2.26137

Corral, V., Fraijo, B., \& Pinheiro, J. (2006). Sustainable behavior and time perspective: present, past and future orientation and their relationships with wáter conservation behavior. Revista latinoamericana de Psicología, 40(2), 139-147.

Corral, V., Fraijo, B., \& Tapia, C. (2004). Propensiones psicológicas en niños de sexto grado de primaria. Validez de un instrumento. Anuario de Investigaciones Educativas, 7, 31-44.

Corral,V., Fraijo, B., \& Tapia, C. (2008). Un registro observacional del consumo individual e agua: aplicaciones a la investigación de la conducta sustentable. Revista Mexicana de Análisis de la Conducta, 34(1), 79-96.
Corral, V., Frías, M., Fraijo, B., \& Tapia, C. (2006). Rasgos de la conducta antisocial como correlatos del actuar anti y proambiental. Medio Ambiente y Comportamiento Humano, 7(1), 89-103.

Corral, V., Garibaldi, L., \& Encinas, L. (1987). Estudio exploratorio de patrones conductuales de consumo doméstico de agua en la zona urbana. Revista Sonorense de Psicología, 2, 87-93.

Corral, V., \& Obregón, F. J. (1992). Modelos predictores del comportamiento proambientalista. Revista Sonorense de Psicología, 5, 5-14.

Corral, V., \& Pinheiro, J. (2004). Aproximaciones al estudio de la conducta sustentable. Medio Ambiente y Comportamiento Humano, 5(1-2), 1-26.

Corral, V., \& Pinheiro, J. (2009). Environmental psychology with a Latin American taste. Journal of Environmental Psychology, 29, 266-374.

Corral, V., \& Zaragoza, F. (2000). Bases sociodemográficas y psicológicas de de la conducta de reutilización. Un modelo estructural. Medio Ambiente y Comportamiento Humano, 1, 9-29.

Dasaklis, T., \& Pappis, C. (2013). Supply chain management in view of climate change: an overview of possible impacts and the road ahead. Journal of Industrial Engineering Management, 6(4), 11241138.

Duerden, M., \& Witt, P. (2010). The impact of direct and indirect experiences on the development of environmental knowledge, attitudes and behavior. Journal of Environmental Psychology, 30(4), 379392. doi: 10.1016/j.jenvp.2010.03.007 
Flores, M., \& Parra, M. (2011). Caracterización del ahorro doméstico de agua en la región de Murcia en función de componentes sociodemográficos. Contribuciones a las Ciencias Sociales, 13, 1-13.

Fondo de las Naciones Unidas para la Infancia -[UNICEF]. (2010). Pobreza infantil en países ricos (UNICEF, Centro de Investigaciones Innocenti, Report card No. 6). Nueva York: Autor. Recuperado de https://www.unicef-irc.org/publications/ pdf/repcard6s.pdf.

Frías, M., Rodríguez, A., \& Corral, V. (2009). Análisis de factores que influyen en el desarrollo de normas ambientales y en conducta anti-ecológica. Revista Interamericana de Psicología, 43(2), 309-322.

García, C. (2012). La cobertura de la prensa en torno a denuncias, abastecimientos y emplazamientos ante una escasez de agua en Iztapalapa, México. Sociedad Hoy, 22, 95-113.

García, C. (2013). El encuadre periodístico en torno a los conflictos hídricos derivados de la mercadocracia en México. Psicología para América Latina, 24, 121-155.

García, C., \& Bustos, J. M. (2013). Los estudios psicológicos de la sustentabilidad hídrica. Aplicaciones al sistema tarifario de consumo. Revista de Ciencias Sociales, 139(1), 65-90.

García, C., Carreón, J., Hernández, J., Mejía, S., García, E., \& Rosas, F. (2015). Hacia una agenda hídrica para la gobernanza local sustentable. Investigación en Ciencias Sociales, 11(1), 130-154.

García, C., Carreón, J., Mecalco, J., Hernández, J., Bautista, M., \& Méndez,A.(2014). Sistemas políticos complejos: Implicaciones para la seguridad pública sustentable. Acciones $e$ Investigaciones Sociales, 34, 184-201.

García, C., Hernández, J., Carreón, J., Mejía, S., Mendoza, D., Aguilar, J., \& Maldonado, F. (2014). Especificación de un modelo de agenda sociopolítica en torno a los conflictos hídricos y la pacificación retributiva. OBETS, 9(2), 249-265. doi: 10.14198/OBETS2014.9.2.01

Gissi,N.,\& Soto,P.(2010). Dela estigmatización al orgullo barrial: Apropiación del espacio e integración social de la población mixteca en una colonia de la Ciudad de México. INVI, 25(68), 99-118.

Groot, J., \& Steg, L. (2010). Relationships between value orientations, self determined motivational types and proenvironmental behavioural intentions. Journal of Environmental Psychology, 30(4), 368-378. doi: 10.1016/j.jenvp. 2010.04.002.

Guering, B. (1994). Attitudes and beliefs as verbal behavior. Behavior Analyst, 17, $155-163$.

Guevara, J., \& Rodríguez, C. (2002). Localización de actitudes proambientales. Revista de Psicología de la Universidad de Chile, 11, 93-109.

Hernández, L., \& Jiménez, E. (2010). Actitudes y comportamiento ambiental del personal de área de conservación marina. Biocenosis, 23(1), 1-12.

Hernández, M., Landazuri, A., Silva, A., \& Terán, A. (2000). Evaluación ambiental de un campus universitario. La Psicología Social en México, 8, 514-521.

Hidalgo, C., \& Pisano, I. (2010). Predictores de la percepción de riesgo y del comporta- 
miento ante el cambio climático. Un estudio piloto. Psyechology, 1(1), 36-49.

Jaén, J., \& Barbudo, P. (2010). Evolución de las percepciones medioambientales de los alumnos de educación secundaria en un curso académico. Revista Eureka, Enseñanza e Investigación Científica, 7, 247-259.

Jiménez, M. (2010). Definición y medición de la conciencia ambiental. Revista Internacional de Sociología, 68, 735-755.

Jiménez, M., \& Lafuente, R. (2010). Definición y medición de la conciencia ambiental. Revista Internacional de Sociología, 68(3), 735-755. doi: 10.3989/ ris.2008.11.03.

Kalantari, K., \& Asadi, A. (2010). Designing a structural model for explained environmental attitude and behavior of urban residents. International Journal for Environmental Research, 4(2), 309-320.

Klôckner, C., \& Blôbaum, A. (2010). A comprensive action determination model: toward a broader understanding of ecological behavior using the example of travel mode choice. Journal fo Environmental Psychology, 30(4), 574586. doi: 10.1016/j.jenvp.2010.03.001.

Leff, E. (2010). Economía ecológica, racionalidad y sustentabilidad. Sustentabilidades, l(2), 128-143.

Leff, E. (2011). Sustentabilidad y racionalidad ambiental: hacia "otro" programa de sociología ambiental. Revista Mexicana de Sociología, 73(1), 5-46.

León, S. (2013). Indicadores de tercera generación para cuantificar la sustentabilidad urbana ¿Avances o estancamiento?. EURE, 39(118), 173-198.
Londoño, C., \& Cardona, H. (2011). Estado del arte de los recursos para el desarrollo. Revista Ciencias Estratégicas, 19(25), 35-54.

Lucca, E. (2010). Sustentabilidad urbana, rural natural. Sustentabilidades, 1(2), 144-161.

Malmod, A. (2011). Lógicas de ocupación en la conformación del territorio. Ordenamiento territorial como instrumento de la planificación. Revista Iberoamericana de Urbanismo, 6, 18-30.

Manríquez, J., \& Montero, M. (2011). Motivación hacia el cuidado del agua en población mexicana. Quaderns de Psicología, 13(1), 25-34.

Markowitz, E. (2012). Is climate change and ethical issue? Examining young adult's beliefs about climate and morality. Climatic Change, 114(3), 479-475. doi:10.1007/s10584-012-0422-8

Martínez, J., \& Montero, M. (2010). Percepción de cualidades restauradoras y preferencia ambiental. Revista Mexicana de Psicología, 27(2), 183-190.

Martínez, J., \& Montero, M. (2011). La percepción de restauración ambiental de la vivienda y el funcionamiento familiar. Quaderns de Psicología, 13(1), 81-89.

McCright, A. (2010). The effects of gender of climate change knowledge and concern in the American public. Population and Environment, 32(1), 66-87. doi: 10.1007/ s11111-010-0113-1.

McCright, A., \& Riley, D. (2011). Cool dudes: the denial of climate change among conservative white males in the United States. Global Environmental Change, 21(4), 1163-1172. doi: 10.1016/j.gloenvcha.2011.06.003. 
Meinhold, J., \& Malkus, A. (2005). Adolescents environmental behaviors. Can knowledge, attitudes, and self efficacy make a difference?. Environment and Behavior, 37, 511-532.

Milfont, T., \& Duckitt, J. (2010). The environmental attitudes inventory: a valid and reliable measure to assess the structure of environmental attitudes. Journal of Environmental Psychology, 30(1), 80-94. doi: 10.1016/j.jenvp.2009.09.001

Montalbetti, T., \& Chamarro, A. (2010). Construcción y validación del cuestionario de percepción de riesgo en escalada de roca. Cuadernos de Psicología del Deporte, 10(2), 43-56.

Moreno, M. (2013). Una lectura prospectiva de la agenda Rio+20. La emergencia de una gobernanza para el Desarrollo Sustentable. Xihmai, 15(8), 57-74.

Moyo, M., Mvupm, B., Kunzekweguta, M., Mazvipavf, F., Crawford, P., \& Dorward, P. (2012). Farmer perceptions on climate change and variability in semiarid Zimbabwe in relation to climatology evidence. AfricanCropScienceJournal, 20, 317-335.

Nozica, G. (2011). Planificar para la integración territorial. Los escenarios deseables de inserción de la provincia de San Juan al Mercosur. Revista Iberoamericana de Urbanismo, 6, 43-54.

Oceja, L., \& Jiménez, I. (2001). Hacia una clasificación psicosocial de las normas. Estudios de Psicología, 22, 227-242.

Pasco, A., Villafuerte, M., \& Neyra, F. (2010). Influencia del conocimiento técniconormativo de la problemática y la actitud ambiental en la toma de decisiones respecto a la estrategia nacional sobre el cambio climático. Revista Aportes, 3, 191-193.

Poortinga, W., Spence, A., Demski, C., \& Pidgeon, N. (2012). Invidiual motivational factors in the acceptability of demand side and supply side measures to reduce carbon emissions. Energy Policy, 48, 812-819.

Quiroz, D. (2013). Las ciudades y el cambio climático: el caso de la política climática de la ciudad de México. Estudios Demográficos y Urbanos, 28(83), 343-382.

Sahin, E., Ertepinar, H., \& Teksoz, G. (2012). University student's behaviors pertaining to sustainability: a structural equation model with sustainable relate attributes. International Journal of Environmental \& Science Education, 7, 459-478.

Schoon, I., Cheng, H., Gale, C., Batty, D., \& Deary, I. (2010). Social status, cognitive ability, and educational attainment as predictors of liberal social attitudes and political trust. Intelligence, 38, 144-150.

Schwartz, N., \& Bohner, G. (2001). The construction of attitudes. En A. Tesser \& N. Schwartz (Eds.), Handbook of Social Psychology (pp. 436-57). Oxford: Blackwell.

Seacat, J., \& Northrup, D. (2010). An information motivation behavioral skills assessment of curbiside recycling behavior. Journal of Environmental Psychology, 30(4), 393-401. doi: 10.1016/j.jenvp. 2010.02.002

Sharples, D. (2010). Communicating climate science: evaluating the UK public's attitude to climate change. Earth and Environment, 5, 185-205. 
Spence, A., Portinga, W., Butler, C., \& Pidgeon, N. (2011). Perception of climate change and willingness to save energy related to flood experience. NatureClimateChange, $1,46-49$.

Touguinha, S., \& Pato, C. (2011). Valores personales, creencias ambientales ecocéntricas y comportamiento ecológico de trabajadores brasileños: el caso del ministerio público del Distrito Federal y territorios. Quaderns de Psicología, 13(19), 35-45.

United Nations Habitat -[UN-HABITAT]. (2010). Sick water? The central role of wastewater management in sustainable. A rapid response assessment. Recuperado de http://www.unep.org/pdf/SickWater screen.pdf.

United Nations Water -[UN-WATER]. (2013). Water security \& the global water agenda. Ontario: United Nations University. Recu- perado de http://www.unwater.org/downloads/analytical_brief_oct2013_web.pdf.

Urbina, J. (2004). Percepción de Riesgos Ambientales: la escasez de agua. La Psicología Social en México, 10, 513-520.

Vinneta, M., \& Maharaj, K. (2013). Environmental conciuosness: and indicator of higher conciousness. International Journal of Scientific and Research Publications, 3, 1-5.

Wendling, Z., Attari, S., Carley, S., Krause, R., Warren, D., Rupp, J., \& Graham, J. (2013). On the importance of strengthening moderate beliefs in climate sciences to foster support for immediate action. Sustainability, 5, 5153-5170.

Zapata, R., \& Castrechini, A. (2011). Conducta Proambiental y personalidad: Análisis de un barrio de Lima. Quaderns de Psicología, 13(1), 47-61. 
Anexo

\section{Estado del conocimiento}

\begin{tabular}{|c|c|c|}
\hline Año & Autor & Hallazgo \\
\hline 1987 & $\begin{array}{c}\text { Corral, Garibaldi } \\
\text { y Encinas }\end{array}$ & $\begin{array}{l}\text { Encontraron en un estudio exploratorio que el uso de la regadera era la principal actividad de } \\
\text { consumo doméstico de agua. En contraste, el uso del refrigerante fue el dispositivo doméstico } \\
\text { con menor frecuencia de empleo. }\end{array}$ \\
\hline 1992 & Corral y Obregón & $\begin{array}{l}\text { Llevaron a cabo una revisión sistemática de las variables incluidas en los modelos de } \\
\text { comportamiento proambiental. Midieron la distancia entre la residencia y el depósito de reciclaje, } \\
\text { las competencias proambientales, los estilos y los motivos ecológicos como los determinantes } \\
\text { del comportamiento proambiental. }\end{array}$ \\
\hline 2000 & Corral y Zaragoza & $\begin{array}{l}\text { Demostraron mediante un sistema de ecuaciones estructurales, cuatro dimensiones del } \\
\text { comportamiento de reciclaje, que se determinó por los motivos de reutilización. En dicho } \\
\text { modelo, el tamaño de la casa y el estatus económico incidieron en el comportamiento. Sin } \\
\text { embargo, las creencias a través de los motivos influyeron en la conducta de reutilización. Los } \\
\text { autores establecieron diferencias significativas entre hombres y mujeres con respecto a sus } \\
\text { conocimientos y creencias sobre reutilización y reciclaje de productos. }\end{array}$ \\
\hline 2000 & Hernández et al., & $\begin{array}{l}\text { Dieron a conocer una diferencia entre proporciones de datos no paramétricos, seis categorías: } \\
\text { imagen e identidad institucional, ambiente físico y construido, residuos sólidos, residuos } \\
\text { peligrosos, manejo de energía eléctrica y formación ambiental. Años después, la imagen } \\
\text { del campus, los residuos sólidos y la formación ambiental seguían siendo los principales } \\
\text { problemas. }\end{array}$ \\
\hline 2001 & Acosta y Montero & $\begin{array}{l}\text { Demostraron asociaciones significativas entre la conducta ambiental responsable, locus de } \\
\text { control, conocimiento de la acción ambiental, habilidades ambientales y estilos de afrontamiento } \\
\text { cognitivo relativos a negación y aceptación del deterioro ambiental. En la medida en que } \\
\text { aumentaban los valores de una variable se incrementaban los valores de la otra. Acosta y Montero } \\
\text { probaron que la conducta ambiental responsable está asociada }(\mathrm{r}=, 45 ; \mathrm{p}<, 05) \text { con el índice de } \\
\text { habilidades y conocimientos de la acción ambiental. }\end{array}$ \\
\hline 2001 & Oceja y Jiménez & $\begin{array}{l}\text { Evaluaron un grupo de normas, analizaron su grado de cumplimiento y establecieron su } \\
\text { clasificación. Demostraron con ello que la tipología es pertinente a partir de tres criterios: } \\
\text { acuerdo personal, sanción formal y desaprobación social. Determinaron diferencias entre las } \\
\text { normas (leyes legítimas y prescripciones se cumplen más que leyes ilegítimas y convicciones) } \\
\text { utilizando el criterio de cumplimiento informado y percibido. Y dieron a conocer diferencias } \\
\text { significativas entre las actitudes hacia cada tipo de norma. }\end{array}$ \\
\hline 2002 & Guevara y Rodríguez & $\begin{array}{l}\text { Probaron la tendencia de residentes de la Ciudad de Puebla a responder positiva y homogéneamente } \\
\text { a la separación de basura y los servicios de recolección. }\end{array}$ \\
\hline 2002 & $\begin{array}{l}\text { Negrón, Arias } \\
\text { y Delbrey }\end{array}$ & $\begin{array}{l}\text { Demostraron diferencias significativas entre hombres y mujeres respecto al cambio de sus } \\
\text { conocimientos, posterior a información relativa a sus conocimientos sobre su salud y el } \\
\text { entorno. }\end{array}$ \\
\hline 2003 & Corral & $\begin{array}{l}\text { Reveló mediante un modelo estructural, la incidencia de utensilios domésticos en el consumo } \\
\text { de agua. En dicho modelo, los motivos, la escasez y las habilidades, tuvieron un efecto negativo } \\
\text { sobre el consumo de agua. }\end{array}$ \\
\hline 2003 & Frías, López y Díaz & $\begin{array}{l}\text { Demostraron el efecto indirecto del macrosistema sobre la conducta antisocial a través } \\
\text { del microsistema. En el modelo estructural, el exosistema contó con tres indicadores y el } \\
\text { microsistema con cinco variables manifiestas. }\end{array}$ \\
\hline
\end{tabular}




\begin{tabular}{|c|c|c|}
\hline Año & Autor & Hallazgo \\
\hline 2004 & $\begin{array}{l}\text { Bustos, Flores } \\
\text { y Andrade }\end{array}$ & $\begin{array}{l}\text { Argumentaron la relación directa, positiva y significativa entre dos variables conductuales } \\
\text { proambientales: lavado de baños con aseo personal }(\mathrm{r}=, 17 ; \mathrm{p}<, 01) \text {, aseo de dientes con baño } \\
\text { personal }(\mathrm{r}=, 18 ; \mathrm{p}<, 01) \text {. La relación entre tres variables conservacionistas: creencias de obligación } \\
\text { de cuidar el agua con habilidades instrumentales de ahorro }(\mathrm{r}=, 24 ; \mathrm{p}, 01) \text {, conocimientos sobre } \\
\text { el manejo de agua con motivos de protección socioambiental }(\mathrm{r}=, 42 ; \mathrm{p}<, 01) \text { y habilidades } \\
\text { instrumentales de ahorro con motivos de protección socioambiental }(\mathrm{r}=, 27 ; \mathrm{p}<, 01) \text {. La relación } \\
\text { entre siete factores proambientales: creencias de obligación de cuidar el agua con locus de control } \\
\text { interno }(\mathrm{r}=, 43 ; \mathrm{p}<, 01) \text {, con el ahorro de agua }(\mathrm{r}=, 45 ; \mathrm{p}<, 01) \text {, con los motivos de protección } \\
\text { ambiental }(\mathrm{r}=, 24 ; \mathrm{p}<, 01) \text {, con la percepción de riesgos a la salud }(\mathrm{r}=, 26 ; \mathrm{p}<, 01) \text {; a su vez la } \\
\text { percepción se asocia con el locus de control interno }(\mathrm{r}=, 30 ; \mathrm{p}<, 01) \text {, con el comportamiento } \\
\text { proambiental }(\mathrm{r}=, 23 ; \mathrm{p}<, 01) \text { y con los motivos de protección ambiental ( } \mathrm{r}=, 27) \text {. Los cuales a su } \\
\text { vez se relacionan con el locus de control }(\mathrm{r}=, 28 ; \mathrm{p}<, 01) \text {, con el ahorro de agua ( } \mathrm{r}=, 12 ; \mathrm{p}<, 01) \\
\text { y con las habilidades instrumentales ( } \mathrm{r}=, 42 ; \mathrm{p}<, 01) \text {, los que a su vez se conectan con el locus } \\
\text { de control }(\mathrm{r}=, 38 ; \mathrm{p}<, 01) \text { y el ahorro de agua ( } \mathrm{r}=, 33 ; \mathrm{p}<, 01) \text {. Finalmente, los conocimientos } \\
\text { del manejo de agua se asocian con el locus de control ( } \mathrm{r}=, 16 ; \mathrm{p}<, 01) \text { y con el comportamiento } \\
\text { proambiental }(\mathrm{r}=, 47 ; \mathrm{p}<, 01) \text {. Demostraron el efecto indirecto de las creencias de control interno } \\
\text { y los conocimientos sobre el comportamiento proambiental. En dicha trayectoria de predicción, } \\
\text { las creencias de obligación de cuidar el agua, la percepción de riesgo, los motivos de protección } \\
\text { socioambiental y las habilidades instrumentales transfirieron dicho impacto. }\end{array}$ \\
\hline 2004 & Corral y Pinheiro & $\begin{array}{l}\text { Establecieron seis dimensiones del comportamiento sustentable: austeridad, anticipación, } \\
\text { altruismo, efectividad, deliberación y ahorro. Demostraron asociaciones positivas y significativas } \\
\text { entre las dimensiones. Posteriormente en un modelo estructural, probaron la reflectividad del } \\
\text { comportamiento sustentable en torno a las seis dimensiones referidas. }\end{array}$ \\
\hline 2004 & Corral, Fraijo y Tapia & $\begin{array}{l}\text { Revelaron cuatro dimensiones del consumo de agua relativas al uso de lavabo, regadera, riego } \\
\text { y limpieza. Posteriormente establecieron mediante un modelo estructural, la incidencia de las } \\
\text { creencias ecológicas y utilitarias en el consumo de agua. Ambas creencias correlacionaron } \\
\text { negativamente. }\end{array}$ \\
\hline 2004 & Urbina & $\begin{array}{l}\text { Evidenció que la contaminación y la escasez del agua son percibidas por habitantes expertos y } \\
\text { no expertos como riesgos. }\end{array}$ \\
\hline 2005 & Aguilar y Valencia & $\begin{array}{l}\text { Estableció mediante un modelo estructural, el efecto indirecto de la actitud, la conducta pasada, } \\
\text { el control y la norma personal sobre el comportamiento proambiental a través de la intención. En } \\
\text { dicha estructura, la conducta pasada fue el principal determinante del comportamiento ecológico. }\end{array}$ \\
\hline 2005 & Fraj y Martínez & $\begin{array}{l}\text { Constataron el efecto moderador del conocimiento ambiental sobre la relación causal entre } \\
\text { el compromiso afectivo, verbal y real. En la medida en que el conocimiento ambiental era } \\
\text { mínimo, el vínculo causal y el porcentaje de varianza eran bajos. En contraste, cuando el nivel } \\
\text { de conocimiento ambiental era especializado, las relaciones causales y la varianza explicada } \\
\text { incrementaban significativamente. }\end{array}$ \\
\hline 2005 & Meinhold y Malkus & $\begin{array}{l}\text { Correlacionaron la autoeficacia con las actitudes ambientales }(\mathrm{r}=, 23) \text {, con los conocimientos } \\
\text { ambientales }(\mathrm{r}=, 16) \text { y con el comportamiento proambiental }(\mathrm{r}=, 30) \text {. Las actitudes ambientales } \\
\text { con los conocimientos ambientales }(\mathrm{r}=, 18) \text { y con el comportamiento proambiental }(\mathrm{r}=, 45) \text { y } \\
\text { los conocimientos ambientales con el comportamiento proambiental }(\mathrm{r}=, 34) \text {, todos con una } \\
\text { significancia menor a }, 001 \text {. }\end{array}$ \\
\hline 2006 & $\begin{array}{l}\text { Corral, Frías, Fraijo } \\
\text { y Tapia }\end{array}$ & $\begin{array}{l}\text { Encontraron diferencias significativas entre el sexo y la edad con respecto a la propensión al } \\
\text { riesgo; entre sexo, edad y escolaridad en cuanto a la falta de autocontrol; entre sexo y edad con } \\
\text { respecto a la conducta antisocial y entre sexo y edad en cuanto a la conducta antiambiental. } \\
\text { Determinaron asociaciones positivas y significativas entre la propensión al riesgo y la falta de } \\
\text { autocontrol, la conducta antisocial y la conducta antiambiental; entre la falta de autocontrol y la } \\
\text { conducta antisocial y antiambiental y entre la conducta antisocial y la conducta antiambiental. } \\
\text { Demostraron asociaciones negativas entre el comportamiento proambiental y la tendencia al } \\
\text { riesgo y la falta de autocontrol. }\end{array}$ \\
\hline
\end{tabular}




\begin{tabular}{|c|c|c|}
\hline Año & Autor & Hallazgo \\
\hline 2007 & $\begin{array}{l}\text { Cerda, García, Díaz } \\
\text { y Núñez }\end{array}$ & $\begin{array}{l}\text { Probaron el efecto directo de la protección ambiental sobre el comportamiento proambiental del } \\
\text { consumidor de productos ecológicos y el promotor de cultura ambiental; la relación causal entre } \\
\text { el fomento a la protección ambiental y el comportamiento ecológico del fiscalizador ambiental y } \\
\text { el promotor cultural ambiental. }\end{array}$ \\
\hline 2008 & $\begin{array}{l}\text { Milfont, Andrade, Belo } \\
\text { y Pessoa }\end{array}$ & $\begin{array}{l}\text { Establecieron asociaciones positivas entre pasado negativo y presente hedonista, pasado positivo } \\
\text { y presente fatalista. El presente hedonista con el pasado positivo y el presente fatalista. }\end{array}$ \\
\hline 2009 & $\begin{array}{l}\text { Corral, Tapia, Fraijo } \\
\text { y González }\end{array}$ & $\begin{array}{l}\text { Dieron a conocer diez dimensiones del comportamiento sustentable: percepción de normas } \\
\text { ambientales, aprecio por lo natural, indignación proambiental, afinidad por la diversidad, } \\
\text { deliberación, equidad, altruismo, proecologismo, austeridad y autopresentación. }\end{array}$ \\
\hline 2009 & $\begin{array}{l}\text { Frías, Rodríguez } \\
\text { y Corral }\end{array}$ & $\begin{array}{l}\text { Probaron mediante un modelo estructural, el efecto de la norma social sobre la conducta } \\
\text { antiambiental. En dicho sistema de ecuaciones, la disuasión y la norma personal tuvieron una } \\
\text { incidencia menor o nula en el comportamiento desfavorable al medioambiente. }\end{array}$ \\
\hline 2009 & $\begin{array}{l}\text { Harranz, Proy } \\
\text { y Eguiguren }\end{array}$ & $\begin{array}{l}\text { A través de un modelo de senderos, establecieron a la intención como determinante principal del } \\
\text { comportamiento de reciclaje. En el sistema de ecuaciones, las creencias influyeron indirectamente } \\
\text { en el reciclaje y la intención fue la variable transmisora. }\end{array}$ \\
\hline 2009 & Orostegui y Matos & $\begin{array}{l}\text { El estrato alto }(62 \mathrm{~kg} / \mathrm{hab} / \text { día }) \text { generó menos residuos que los estratos medio ( } 74 \mathrm{~kg} / \mathrm{hab} / \mathrm{dí}) \text { y } \\
\text { bajo }(77 \mathrm{~kg} / \mathrm{hab} / \mathrm{día}) \text { y con respecto a la media distrital }(71 \mathrm{~kg} / \mathrm{hab} / \text { día }) \text {. La materia orgánica, el } \\
\text { papel y el cartón fueron los residuos municipales prevalecientes. En tal sentido, el estrato alto } \\
\text { produjo residuos reciclajes. }\end{array}$ \\
\hline 2010 & $\begin{array}{l}\text { Fernández, Porter } \\
\text { y Neyra }\end{array}$ & $\begin{array}{l}\text { Encontraron diferencias entre profesores y alumnos respecto a su entorno de aprendizaje. } \\
\text { Mientras que los estudiantes consideraban que su entorno tenía relevancia social, los docentes } \\
\text { asumían al entorno natural como el factor de desarrollo más importante para su comunidad. }\end{array}$ \\
\hline 2010 & Gissi y Soto & $\begin{array}{l}\text { Para los autores la apropiación del espacio se gesta con el tequio, que es el trabajo personal que } \\
\text { realiza un integrante del colectivo antes de entrar a la labor comunitaria. }\end{array}$ \\
\hline 2010 & Hidalgo y Pisano & $\begin{array}{l}\text { Relacionaron la actitud con los conocimientos }(\mathrm{r}=0,454 ; \mathrm{p}=0,001) \text {, la autoeficacia con los } \\
\text { conocimientos y las actitudes }(\mathrm{r}=0,303 \mathrm{y} \mathrm{r}=0,882 ; \mathrm{p}=0,001 \text { respectivamente), la percepción } \\
\text { de riesgo con el conocimiento, actitud y autoeficacia }(\mathrm{r}=0,475 ; \mathrm{r}=0,589 \text { y } \mathrm{r}=0,547 ; \mathrm{p}= \\
0,001 \text { respectivamente) y la intención con el conocimiento, actitud, autoeficacia, percepción e } \\
\text { intención }(\mathrm{r}=0,206 ; \mathrm{r}=0,317 ; \mathrm{r}=0,390 \mathrm{y} \mathrm{r}=0,382 ; \mathrm{p}=0,001 \text { respectivamente). La percepción } \\
\text { de riesgo fue determinada por la actitud }(\beta=0,305 ; \mathrm{p}=0,000) \text { y la intención fue influida por la } \\
\text { autoeficacia }(\beta=0,259 ; \mathrm{p}=0,001) \text {. }\end{array}$ \\
\hline 2010 & Jiménez y Lafuente & $\begin{array}{l}\text { Estableció tres factores de las cuatro dimensiones posibles. El primer factor explicó el } 46,4 \% \text { de } \\
\text { la varianza, el segundo el } 28,6 \% \text { y el tercero explicó el } 25,15 \% \text { de la varianza. Determinaron } \\
\text { diferencias entre hombres y mujeres }[\mathrm{X} 2=10,088(2 \mathrm{gl}), \mathrm{p}=0,007] \text {, por años }[\mathrm{X} 2=176,77 \text { ( } \\
\mathrm{gl}), \mathrm{p}=0,000] \text { y hábitat }[\mathrm{X} 2=21,657(6 \mathrm{gl}), \mathrm{p}=0,001] \text {. }\end{array}$ \\
\hline 2010 & Mariby & $\begin{array}{l}\text { En su estudio, el } 62 \% \text { estuvo de acuerdo en una definición de cooperativismo, el } 32 \% \text { tiene una } \\
\text { actitud favorable frente al trabajo colectivo, pero el } 35 \% \text { estuvo en desacuerdo en transformar } \\
\text { su empresa en una cooperativa. }\end{array}$ \\
\hline 2010 & McCright & $\begin{array}{l}\text { Según el autor la ideología política y la percepción de comprensión determinaron negativamente } \\
\text { al conocimiento sobre el cambio climático y la preocupación por sus consecuencias en el género } \\
(\beta=-0,372 \text { y } \beta=0,336 \text { respectivamente). }\end{array}$ \\
\hline 2010 & Molini y Salgado & $\begin{array}{l}\text { Descubrieron que en torno a la discusión sobre las diferencias entre ciudad compacta y dispersa, } \\
\text { la densidad poblacional es un factor relevante, ya que la baja concentración en las ciudades com- } \\
\text { pactas las hacen más sustentables que las ciudades dispersas, pero su alta densidad incrementa } \\
\text { los costos a la entidad gubernamental responsable de regularlas. Tal panorama afecta la creación } \\
\text { de unifamiliares, que se dan en comunidades con más de quinientos mil habitantes y presionan } \\
\text { la disponibilidad de recursos. }\end{array}$ \\
\hline 2010 & $\begin{array}{l}\text { Montilla, Pernía } \\
\text { y Rodríguez }\end{array}$ & $\begin{array}{l}\text { Para los investigadores, el cooperativismo supone un sistema humano y social indicado por pro- } \\
\text { cesos de autoconstrucción, autoproducción, autoorganización y autopoiesis. }\end{array}$ \\
\hline
\end{tabular}




\begin{tabular}{|c|c|c|}
\hline Año & Autor & Hallazgo \\
\hline 2010 & $\begin{array}{c}\text { Pasco, Villafuerte } \\
\text { y Neyra }\end{array}$ & $\begin{array}{l}\text { Demostraron que el nivel de conocimiento técnico-normativo en torno al Programa Nacional } \\
\text { sobre el Cambio Climático era mínimo entre quienes se encargan de tomar decisiones y capacitar } \\
\text { a los voluntarios que efectuarán acciones de preservación ambiental. }\end{array}$ \\
\hline 2010 & $\begin{array}{c}\text { Schoon, Cheng, Gale, } \\
\text { Batty y Deary }\end{array}$ & $\begin{array}{l}\text { Señalaron que las actitudes hacia el liberalismo social fueron determinadas por la educación ( } \beta \\
=, 25) \text {, y que dichas actitudes estuvieron integradas por variables manifiestas de antirracismo, } \\
\text { liberalismo social y equidad de género }(, 45,, 57 \mathrm{y}, 47 \text { respectivamente). }\end{array}$ \\
\hline 2010 & Sharples & $\begin{array}{l}\text { Reveló que la fuente principal de información sobre el cambio climático fueron los noticiarios de } \\
\text { televisión }(23,9 \%) \text {; los alimentos y bebidas son los más consumidos por la muestra }(83,8 \%) \text { y } \\
\text { los focos fueron el objeto más utilizado para combatir el cambio climático }(88,7 \%) \text {. }\end{array}$ \\
\hline 2011 & $\begin{array}{l}\text { Corral, Mireles, Tapia } \\
\text { y Fraijo }\end{array}$ & $\begin{array}{l}\text { Establecieron mediante un modelo estructural }\left[\chi^{2}=144,36(85 \mathrm{gl}), \mathrm{p}<0,001 ; \mathrm{NNFI}=0,97 ;\right. \\
\left.\mathrm{CFI}=0,97 ; \mathrm{RMSEA}=0,03 ; \mathrm{R}^{2} \text { conducta proecológica }=0,52\right] \text { la influencia del comportamiento } \\
\text { sustentable sobre la felicidad }(0,31) \text {. El factor determinante se reflejó en cuatro dimensiones: fru- } \\
\text { galidad, equidad, altruismo y conducta proecológica }(0,42,0,35,0,66 \text { y } 0,72 \text { respectivamente }) \text {. }\end{array}$ \\
\hline 2011 & Flores y Parra & $\begin{array}{l}\text { Dieron cuenta de las diferencias significativas entre densidad, actividad, estudios, ingresos y uso } \\
\text { de agua con respecto al ahorro de agua ocasional, sistemático y ausente. }\end{array}$ \\
\hline 2011 & $\begin{array}{l}\text { Gaxiola, Frías } \\
\text { y Figuerero }\end{array}$ & $\begin{array}{l}\text { Probaron mediante un modelo estructural }\left[\chi^{2}=14,6(5 \mathrm{gl}), \mathrm{p}<0,01 ; \mathrm{BBNFI}=0,90 ; \mathrm{BBNNFI}=\right. \\
\left.0,86 ; \mathrm{CFI}=0,96 ; \mathrm{RMSEA}=0,04 ; \mathrm{R}^{2}=0,05\right] \text { cinco factores reflejantes de factores protectores. } \mathrm{La} \\
\text { variable latente incluyó al factor } k(0,65) \text {, exosistema }(0,27) \text {, microsistema }(0,79) \text {, ontosistema } \\
(0,64) \text { y crianza }(0,22) \text {. }\end{array}$ \\
\hline 2011 & Malmod & $\begin{array}{l}\text { Sistematizó los planes de reordenamiento a partir de una lógica de exclusión e inclusión. La } \\
\text { primera consistió en diferenciar los espacios; privatización de bienes y servicios. La segunda } \\
\text { fijó conexiones entre los sectores, espacios y servicios para aminorar la segregación espacial. La } \\
\text { lógica de inclusión implica un diseño de redes en el que cada nodo se interconecta con el otro y } \\
\text { permite la interrelación entre los elementos espaciales, así como la construcción de una identidad } \\
\text { urbana que favorece la tolerancia a la diversidad. }\end{array}$ \\
\hline 2011 & $\begin{array}{l}\text { Marqués, Salavarría, } \\
\text { Eastmond, Ayala, } \\
\text { Arteaga, Marqués, } \\
\text { Valladares y Manzanero }\end{array}$ & $\begin{array}{l}\text { Encontraron en una muestra de estudiantes de una universidad pública un nivel de conocimien- } \\
\text { to medio de los problemas ambientales generales y específicos en referencia a sus actitudes y } \\
\text { comportamientos. }\end{array}$ \\
\hline 2011 & McCright y Dunlap & $\begin{array}{l}\text { Evidenciaron que las creencias sobre los efectos nulos del cambio climático determinaron la } \\
\text { confianza en los hombres blancos con ideología conservadora }(\gamma=0,82 ; p=0,000) \text {. Por su par- } \\
\text { te, la ideología política de base determinó la negación de los efectos del cambio climático }(\gamma= \\
0,47 ; p=0,000) \text {, la raza determinó la creencia acerca de la falta de consenso de los efectos del } \\
\text { cambio climático para los blancos conservadores }(\gamma=0,38 ; p=0,000) \text {. Empero, el sexo incidió } \\
\text { negativamente en las creencias de los efectos nulos del cambio climático de los encuestados base } \\
(\gamma=-0,67 ; p=0,000) \text {, así como la influencia de la identificación con el ambientalismo sobre la } \\
\text { misma creencia en el mismo grupo }(\gamma=-0,81 ; p=0,000) \text {. }\end{array}$ \\
\hline 2011 & Nacif y Espinosa & $\begin{array}{l}\text { Hallaron una relación entre la identidad nacional y el pragmatismo urbanista del reordenamien- } \\
\text { to espacial central y los diseños arquitectónicos. Las edificaciones representaron símbolos de } \\
\text { reconstrucción nacional que se extenderían a otras ciudades pamperas y sudamericanas (Brasil, } \\
\text { Perú, Colombia y Venezuela). Las propuestas arquitectónicas de la época planteaban una mayor } \\
\text { movilidad de este a oeste tratando de integrar a la periferia con el centro. De este modo, el campo } \\
\text { se articularía con la ciudad y los sistemas hídricos podrían tener un mayor aprovechamiento, aun- } \\
\text { que la región minera se apartaba cada vez más de los servicios públicos. En tal esquema, las vías } \\
\text { férreas fueron fundamentales para incorporar los sectores primarios, secundarios y terciarios. } \\
\text { Por ello, las bodegas debían trasladarse a las zonas agroindustriales. Debido a que la ciudad fue } \\
\text { devastada por un sismo y los espacios de resguardo fueron nulos o insuficientes, se proyectaron } \\
\text { parques recreativos que cumplieron con la función espacial sísmica y recreativa. Para evitar el } \\
\text { aglutinamiento de transporte, se proponía la construcción de un arco. Respecto al reordenamien- } \\
\text { to vecinal, la creación de barrios de quince manzanas en espacios arrendados garantizaba el } \\
\text { control socioespacial del Estado. Otras propuestas consistieron en concentrar a la ciudadanía en } \\
\text { áreas multiculturales para evitar la segregación. Dos temas resultaron fundamentales: la conser- } \\
\text { vación ambiental y la privatización del territorio. }\end{array}$ \\
\hline
\end{tabular}




\begin{tabular}{|c|c|c|}
\hline Año & Autor & Hallazgo \\
\hline 2011 & Nozica & $\begin{array}{l}\text { Demostró que la política de turismo incentiva la conexión entre corredores bioceánicos y pe- } \\
\text { riurbanos. Para tal propósito el escenario deseable consistirá en una red vial que articule ambas } \\
\text { áreas. Tal estrategia permitirá incrementar las ventajas competitivas en materia de servicios tu- } \\
\text { rísticos, tecnológicos y comerciales de la región. }\end{array}$ \\
\hline 2011 & Puntriano & $\begin{array}{l}\text { Probó que la quiebra del ingenio generó un emprendimiento en los campesinos y empleados que } \\
\text { decidieron administrar la empresa luego de que los conflictos entre los actores se resolvieron con } \\
\text { la expropiación en el marco del neoliberalismo. }\end{array}$ \\
\hline 2011 & Solis & $\begin{array}{l}\text { Para el autor el sentido de responsabilidad ambiental determinó directa, positiva y significativa- } \\
\text { mente al ahorro de agua de uso doméstico y residencial. La afinidad emocional con el medioam- } \\
\text { biente influyó en el manejo residencial de residuos sólidos municipales. }\end{array}$ \\
\hline 2011 & $\begin{array}{l}\text { Spence, Portinga, } \\
\text { Butler y Pidgeon }\end{array}$ & $\begin{array}{l}\text { Reportaron que la prevención de desastres percibidos influyó en la reducción de consumo de } \\
\text { energía }(\beta=0,371) \text {, así como la experiencia de inundación determinó la vulnerabilidad local } \\
\text { percibida }(\beta=0,421) \text {. }\end{array}$ \\
\hline 2011 & Touginha y Pato & $\begin{array}{l}\text { Señalaron que el comportamiento ecológico correlacionó con la edad }(\mathrm{r}=0,30) \text {, mientras que las } \\
\text { creencias ecocéntricas se asociaron con los valores universales }(\mathrm{r}=0,20) \text {. Por su parte, la edad y } \\
\text { los valores universales determinaron el comportamiento ecológico }(\beta=0,24 ; \beta=0,21 ; \mathrm{p}=0,001 \\
\text { respectivamente). }\end{array}$ \\
\hline 2011 & Zapata y Castrechini & $\begin{array}{l}\text { Hallaron diferencias significativas entre los residentes de zonas cercanas respecto al neuroticis- } \\
\text { mo, extraversión y reciclaje. Los rasgos de la personalidad no se asociaron significativamente } \\
\text { con el comportamiento proambiental de reciclaje. }\end{array}$ \\
\hline 2012 & $\begin{array}{c}\text { Carr, Patterson, Yung } \\
\text { y Spencer }\end{array}$ & $\begin{array}{l}\text { En su estudio, las personas con creencias religiosas coincidieron en que estas están muy conecta- } \\
\text { das con los efectos del cambio climático, mientras que los escépticos manifestaron su confianza } \\
\text { en los avances científicos y tecnológicos, más que en la solidaridad religiosa ante la problemática } \\
\text { del calentamiento global. }\end{array}$ \\
\hline 2012 & $\begin{array}{c}\text { Corral, García, Tapia } \\
\text { y Fraijo }\end{array}$ & $\begin{array}{l}\text { Establecieron mediante un modelo estructural }\left[\chi^{2}=540,80(243 \mathrm{gl}), \mathrm{p}<0,001 ; \mathrm{BBNNFI}=0,93 \text {; }\right. \\
\left.\mathrm{CFI}=0,94 ; \mathrm{RMSEA}=0,06 ; \mathrm{R}^{2}=0,35\right] \text { los indicadores del factor de conducta sustentable que } \\
\text { incluyó: altruismo, proecologismo, frugalidad y equidad }(0,74,0,75,0,64 \text { y } 0,74 \text { respectiva- } \\
\text { mente), mientras que el factor de restauración comprendió: bienestar, fascinación, extensión y } \\
\text { compatibilidad }(0,61,0,99,0,94 \text { y } 0,99 \text { respectivamente). }\end{array}$ \\
\hline 2012 & Cravino & $\begin{array}{l}\text { Encontró un grado de percepción de riesgo en los residentes bonaerenses al momento de migrar } \\
\text { a la periferia. En este sentido, la percepción del hábitat se relaciona con los servicios y las inver- } \\
\text { siones que el Estado ha orientado a la centralidad. Otro factor de percepción de la vivienda es la } \\
\text { socialización espacial, ya que un cambio de barrio implica la pérdida de capital social. El alquiler } \\
\text { es un fenómeno estrechamente conectado con las expectativas de apropiación del espacio, puesto } \\
\text { que un buen raíz garantiza la permanencia en el barrio y el establecimiento de una mayor calidad } \\
\text { de vida. La proximidad entre las viviendas ha propiciado el desarrollo de una identidad espacial } \\
\text { que incrementa la reciprocidad e incluso la transformación del entorno. }\end{array}$ \\
\hline 2012 & $\begin{array}{c}\text { Fraijo, Corral, Tapia } \\
\text { y García }\end{array}$ & $\begin{array}{l}\text { Establecieron las correlaciones entre los factores psicológicos ambientales. La austeridad corre- } \\
\text { lacionó con la deliberación }(\mathrm{r}=0,311 ; \mathrm{p}=0,001) \text { y con las habilidades }(\mathrm{r}=0,382 ; \mathrm{p}=0,001) \text {. La } \\
\text { deliberación con el altruismo }(\mathrm{r}=0,415 ; \mathrm{p}=0,001) \text {, con la propensión al futuro }(\mathrm{r}=0,390 ; \mathrm{p}= \\
0,001) \text {, con las creencias }(\mathrm{r}=0,336 ; \mathrm{p}=0,001) \text { y con la equidad }(\mathrm{r}=0,302 ; \mathrm{p}=, 001) \text {. El altruismo } \\
\text { con las creencias }(\mathrm{r}=0,279 ; \mathrm{p}=0,001) \text {. El comportamiento proambiental con las habilidades }(\mathrm{r} \\
=0,291 ; \mathrm{p}=0,001) \text {. La propensión al futuro con las creencias }(\mathrm{r}=0,323 ; \mathrm{p}=0,001) \text { y con las } \\
\text { habilidades }(\mathrm{r}=0,321 ; \mathrm{p}=, 001) \text {. Los motivos con las creencias }(\mathrm{r}=0,207 ; \mathrm{p}=0,001) \text {. }\end{array}$ \\
\hline 2012 & Markowitz & $\begin{array}{l}\text { Fijó diferencias entre éticos, no éticos e indecisos con respecto a su preocupación }(\mathrm{F}=102,52 ; \mathrm{p} \\
=0,000) \text {, riesgos }(\mathrm{F}=51,68 ; \mathrm{p}=0,000) \text {, consenso }(\mathrm{F}=26,83 ; \mathrm{p}=0,000) \text {, eficacia }(\mathrm{F}=34,67 ; \mathrm{p} \\
=0,000) \text { y responsabilidad }(\mathrm{F}=69,41 ; \mathrm{p}=0,000) \text {. Las intenciones ambientales fueron determi- } \\
\text { nadas por las creencias }(\beta=0,506) .\end{array}$ \\
\hline
\end{tabular}




\begin{tabular}{|c|c|c|}
\hline Año & Autor & Hallazgo \\
\hline 2012 & $\begin{array}{l}\text { Moyo, Mvupm, } \\
\text { Kunzekweguta, } \\
\text { Mazvipavf, Crawford } \\
\text { y Dorward }\end{array}$ & $\begin{array}{l}\text { Indicaron que el ciclo percibido de la lluvia fue el fenómeno que más recordaron los agricultores } \\
(72 \%) \text {, mientras que el invierno fue el evento menos recordado ( } 1 \% \text { ). Las cuatro estaciones fue- } \\
\text { ron rememoradas como los fenómenos de mayor cambio ( } 23 \%) \text {, por último, el cambio climático } \\
\text { se identificó como la causa principal de los cambios percibidos ( } 53 \% \text { ). }\end{array}$ \\
\hline 2012 & $\begin{array}{l}\text { Poortinga, Spence, } \\
\text { Demski y Pidgeon }\end{array}$ & $\begin{array}{l}\text { Apuntaron que las normas personales determinaron al tamaño de la demanda de carbono y al } \\
\text { suministro de tecnologías alternativas ( } \beta=, 51 \text { y } \beta=, 41 \text { respectivamente). A su vez, las creencias } \\
\text { sobre el cambio climático incidieron en las normas personales }(\beta=, 59) \text {; por su parte, la identidad } \\
\text { ambiental determinó a las creencias de cambio climático }(\beta=, 55) \text {. }\end{array}$ \\
\hline 2012 & $\begin{array}{l}\text { Sahin, Hamide } \\
\text { y Teksoz }\end{array}$ & $\begin{array}{l}\text { Demostraron que el comportamiento favorable al medioambiente lo explicaron las actitudes ha- } \\
\text { cia el mismo }(\beta=, 67) \text {. En su caso, las disposiciones hacia los comportamientos a favor de la } \\
\text { sustentabilidad fueron determinadas por la tendencia a seguir los medios de comunicación }(\beta= \\
\text {,12), aunque también se explicaron por la edad }(\beta=-, 65) \text {. }\end{array}$ \\
\hline 2012 & Urquieta y Campillo & $\begin{array}{l}\text { Establecieron una relación entre los recursos económicos y la estratificación social con respecto } \\
\text { a la representación de la ciudad. Las clases bajas percibieron a la centralidad como un área in- } \\
\text { segura. Las clases medias se mostraron preocupadas por la expansión de la ciudad y sus efectos } \\
\text { en el medioambiente. En cuanto a las expectativas, manifestaron un ideal de ciudad en la que } \\
\text { los espacios permitirían la convivencia como elemento de inclusión; recuperación de espacios, } \\
\text { tranquilidad y disfrute. Respecto al derecho a la ciudad, esta se representó como un escenario de } \\
\text { libertades en las que son indispensables el acceso al empleo, la educación y la salud universales. }\end{array}$ \\
\hline 2012 & $\begin{array}{c}\text { Yahya, Hashemnia } \\
\text { y Rouhi }\end{array}$ & $\begin{array}{l}\text { Probaron que la actitud correlacionó con el consumo de productos verdes }\left(\mathrm{R}^{2}=0,457\right) \text {. La norma } \\
\text { se relacionó con las actitudes }\left(\mathrm{R}^{2}=0,48\right) \text {, las percepciones con las actitudes }\left(\mathrm{R}^{2}=0,43\right) \text { y el } \\
\text { consumo con las actitudes }\left(\mathrm{R}^{2}=0,54\right) \text {. }\end{array}$ \\
\hline 2013 & $\begin{array}{l}\text { Beck, Sinatra } \\
\text { y Lombardi }\end{array}$ & $\begin{array}{l}\text { Para los autores la percepción del conocimiento correlacionó con la preocupación }(\mathrm{r}=0,556) \text {, la } \\
\text { responsabilidad }(\mathrm{r}=0,443 ; \mathrm{p}=0,000) \text { y la preocupación con la responsabilidad }(\mathrm{r}=0,528 ; \mathrm{p}= \\
0,000) \text { y con la responsabilidad de difusión }(\mathrm{r}=0,228 ; \mathrm{p}=0,000) \text {; la responsabilidad personal } \\
\text { con la enseñanza }(\mathrm{r}=0,290 ; \mathrm{p}=0,000) \text {, las predicciones de los estudiantes con sus conocimien- } \\
\text { tos }(\mathrm{r}=0,496 ; \mathrm{p}=0,000) \text { y la responsabilidad de enseñanza con los sentimientos de comodidad ( } \\
=0,529 ; \mathrm{p}=0,000) \text {. Establecieron diferencias entre estudiantes de ciencia, ingeniería, negocios, } \\
\text { salud, artes y educación }\left(\mathrm{v}_{\text {Cramer }}=0,0001\right) \text { y la responsabilidad }(\mathrm{v}=0,000) \text {, sentimientos de con- } \\
\text { fort }(\mathrm{v}=0,000) \text { y enseñanza }(\mathrm{v}=0,000) \text {. }\end{array}$ \\
\hline 2013 & Corral et al. & $\begin{array}{l}\text { Hallaron que las virtudes fueron configuradas por los factores de humanismo, justicia y valo- } \\
\text { ración }(0,97,0,98 \text { y } 0,94) \text {, mientras que el comportamiento sustentable incluyó los factores de } \\
\text { altruismo, proecologismo, frugalidad y equidad }(0,63,0,62,0,79 \text { y } 0,74) \text {. Las virtudes de la } \\
\text { humanidad determinaron el comportamiento sustentable }(\beta=0,67) \text {. }\end{array}$ \\
\hline 2013 & $\begin{array}{c}\text { Corral, Tapia, Ortiz } \\
\text { y Fraijo }\end{array}$ & $\begin{array}{l}\text { Establecieron mediante un modelo estructural }\left[\chi^{2}=641,82(201 \mathrm{gl}), \mathrm{p}<0,0001 ; \mathrm{BBNFI}=0,91 \text {; }\right. \\
\mathrm{CFI}=0,92 ; \mathrm{RMSEA}=0,06] \text { dos factores de primer orden, virtudes y conducta sustentable, que } \\
\text { tuvieron una correlación positiva }(0,67) \text {. Incluyeron tres factores (humanidad, justicia y modera- } \\
\text { ción) de segundo orden para el caso de las virtudes }(0,97,0,97 \text { y } 0,94 \text { respectivamente) y cuatro } \\
\text { (altruismo, proecología, frugalidad y equidad) de segundo orden para el caso de la conducta } \\
\text { sustentable }(0,63,0,69,0,79 \text { y } 0,74) \text {. }\end{array}$ \\
\hline 2013 & $\begin{array}{l}\text { Cunsolo, Harper, Ford, } \\
\text { Edge, Ladman, Houle, } \\
\text { Blake y Wolfrey }\end{array}$ & $\begin{array}{l}\text { Revelaron que el cambio climático se relaciona intuitivamente con el bienestar y la identidad } \\
\text { comunitaria. En ese sentido, sus entrevistados atribuyen vínculos espirituales con su entorno. El } \\
\text { bienestar se asocia con las relaciones que los entrevistados fijan con su entorno y las atribuciones } \\
\text { hacia los elementos circundantes. La salud está representada por la identidad y atribución que el } \\
\text { entorno genera. Las emociones que se desprenden ante el cambio climático son depresión, mie- } \\
\text { do, frustración, devastación y estrés por las amenazas al equilibrio ecológico del ambiente y la } \\
\text { comunidad. En el caso de la depresión, la comunidad reportó una alta incidencia en el consumo } \\
\text { de sustancias adictivas e ideación suicida. Además, el impacto se magnifica al considerar que las } \\
\text { futuras generaciones sufrirán aún más los efectos nocivos del cambio climático en su entorno co- } \\
\text { munitario. Sin embargo, la comunidad también empezó a desarrollar estrategias de cooperación } \\
\text { orientadas a la prevención y protección civil. Se observaron acciones resilientes de autocuidado } \\
\text { y autogestión de la salud pública. }\end{array}$ \\
\hline
\end{tabular}




\begin{tabular}{|c|c|c|}
\hline Año & Autor & Hallazgo \\
\hline 2013 & Dasaklis y Pappis & $\begin{array}{l}\text { La literatura que revisaron los autores atribuye una relevancia mayor al cambio climático en los } \\
\text { procesos productivos y administrativos. Principalmente en cuanto al diseño de procesos y opera- } \\
\text { ciones que reduzcan el impacto del cambio climático sobre el entorno. Se trata de una responsa- } \\
\text { bilidad ambiental generada desde una agenda verde, pero establecida a partir de la minimización } \\
\text { de costos operativos. }\end{array}$ \\
\hline 2013 & Frías y Corral & $\begin{array}{l}\text { Establecieron mediante un modelo estructural }\left[\chi^{2}=197,15(71 \mathrm{gl}), \mathrm{p}<0,001 ; \mathrm{BBNFI}=0,90 \text {; }\right. \\
\left.\text { BBNNFI }=0,91 ; \mathrm{CFI}=0,93 \text {; RMSEA }=0,007 ; \mathrm{R}^{2}=0,67\right] \text { las características individuales de } \\
\text { los delincuentes, que son determinantes de la conducta antisocial }(0,62) \text {. Estas últimas fueron } \\
\text { determinadas por la violencia familiar }(0,42) \text { y el ambiente social }(0,41) \text {. Las características } \\
\text { individuales fueron: ansiedad }(0,84) \text {, conducta opuesta }(0,68) \text {, ADHD }(0,85) \text {, depresión }(0,67) \text {, } \\
\text { desatención }(0,84) \text {, baja empatía }(0,47) \text { y bajo autocontrol }(0,53) \text {. La conducta antisocial incluyó } \\
\text { la antisocialización }(0,76) \text {, agresión }(0,99) \text { y desviación }(0,98) \text {. }\end{array}$ \\
\hline 2013 & $\begin{array}{l}\text { Tapia, Corral, Fraijo y } \\
\text { Durón }\end{array}$ & $\begin{array}{l}\text { Establecieron mediante un modelo estructural }\left[\chi^{2}=382,3(243 \mathrm{gl}), \mathrm{p}<0,0001 ; \mathrm{NNFI}=0,93 \text {; }\right. \\
\left.\text { RMSEA }=0,003 ; \mathrm{R}^{2}=0,57\right] \text { la predicción de la felicidad a partir del comportamiento sustentable } \\
(0,17) \text { y este a partir de la intención conductual }(0,76) \text {. A su vez, el comportamiento sustentable } \\
\text { fue determinado por la conducta proecológica }(0,80) \text {, la frugalidad }(0,66) \text {, la equidad }(0,45) \text { y el } \\
\text { altruismo }(0,41) \text {. Por último, la intención fue influida por la indignación }(0,26) \text { y por la afinidad } \\
(0,34) \text {. }\end{array}$ \\
\hline 2013 & Vinneta y Maharaj & $\begin{array}{l}\text { Para los autores la autotrascendencia se relacionó positiva y significativamente con las actitudes } \\
\text { hacia sí mismo }(0,73) \text {. }\end{array}$ \\
\hline 2013 & $\begin{array}{l}\text { Wendling, Attari, } \\
\text { Carley, Krause, } \\
\text { Warren, Rupp y } \\
\text { Graham }\end{array}$ & $\begin{array}{l}\text { Evidenciaron que el ingreso determinó las preferencias de acción ante el cambio climático }(\beta= \\
0,977 ; p=0,000) \text {. }\end{array}$ \\
\hline
\end{tabular}

Fuente: García y Bustos, 2013. 